\title{
Las organizaciones de la sociedad civil latinoamericana y su oferta de valor. Estudio de caso: México, Brasil, Colombia y Argentina
}

\author{
Erli Margarita Marín Aranguren* \\ Natalia Millares Abella**
}

\section{RESUMEN}

A través de los años, la sociedad civil ha recobrado importancia y se ha convertido en un agente vital de desarrollo, como respuesta a las nuevas apuestas que ha traído el siglo xxI. Sin embargo, sectores como el Gobierno y el mercado no han reconocido la gran importancia que esta ha tenido $y$, por el contrario, ha sido invisibilizada por ambos. En esta investigación se pretende establecer la oferta de valor -concepto que aún está en desarrollo- que ostentan las organizaciones de la sociedad civil en América Latina. Específicamente se estudiarán los casos de México, Brasil, Colombia y Argentina, en temas tan trascendentales como el medio ambiente y la violencia basada en género. La oferta de valor se verá representada por medio de las capacidades técnicas y legales, las propuestas alternativas e innovadoras y las metodologías que estas organizaciones latinoamericanas de

* MA en Relaciones Internacionales, University of Wollongong (Australia); Magíster en Estudios Políticos, otorgado por la Universidad Javeriana, Bogotá (Colombia). Profesora titular e investigadora CIPE - Facultad de Finanzas, Gobierno y Relaciones Internacionales, Universidad Externado de Colombia, Bogotá (Colombia) [erli. marin@uexternado.edu.co].

** Estudiante de noveno semestre del programa de Gobierno y Relaciones Internacionales. Facultad de Finanzas, Gobierno y Relaciones Internacionales Universidad Externado de Colombia, Bogotá (Colombia). [natalia.ma93@ gmail.com].

Recibido: 29 de junio de 2016/ Modificado: 26 de octubre de 2016/ Aceptado: 28 de noviembre de 2016 Para citar este artículo

Marín Aranguren, E. M. y Millares Abella, N. (2017). Las organizaciones de la sociedad civil latinoamericana y su oferta de valor. Estudio de caso: México, Brasil, Colombia y Argentina. OAsis, 25, pp. 187-221.

DOI: https://doi.org/10.18601/16577558.n25.11 
la sociedad civil desarrollan para buscar la protección y la reivindicación de los derechos de los ciudadanos. En conclusión, se busca visibilizar esa oferta de valor de las organizaciones, que en muchas ocasiones es ignorada, y así darle la importancia que estas se merecen al ser copartícipes en el establecimiento de una cultura de desarrollo.

Palabras clave: género, mujer, sociedad civil, políticas públicas, violencias.

\section{Latin American Civil Society Organizations and its Value Offer. Case study: Mexico, Brazil, Colombia and Argentina}

\section{ABSTRACT}

Throughout the years, civil society has gained importance and has become a significant agent of development. This is the result of challenges that have been brought by the twenty-first century. However, sectors such as the government and the market have not recognized the huge importance that society has had. Furthermore, it has been immobilised by both. This research aimed to establish the value offer held by Latin American civil society organizations. The concept of value offer is still under construction. Specifically, we will study the cases of Mexico, Brazil, Colombia and Argentina in issues such as the environment and gender violence. The value offer will be represented by means of the technical and legal capabilities, alternative and innovative proposals, and the methodologies that these Latin American civil society organizations develop in order to seek the protection and the vindication of the rights of the citizens. In conclusion, we seek to make the value of organizations visible, which in many cases is ignored, and thereby give them the importance that they deserve as participants in the establishment of developed culture.

Key words: Gender, women, civil society, public policy, violence.

Sobre la base del reconocimiento de la sociedad civil como actor de desarrollo por derecho propio, que fue planteado en la Declaración de París y, desarrollado en la Agenda de Acción de Accra (AAA), en este artículo se analiza la oferta de valor de Organizaciones de la Sociedad Civil (osc) en América Latina, en temas como medio ambiente y las violencias basadas en género. De manera puntual, se tomarán como caso de estudio cuatro países significativos de la región: México ${ }^{1}$,

\footnotetext{
1 Según el World Factbook de la Agencia Central de Inteligencia de Estados Unidos (CIA) "Mexico has become the United States' second-largest export market and third-largest source of imports. In 2014, two-way trade in goods and services exceeded $\$ 590$ billion. Mexico has free trade agreements with 46 countries, putting more than $90 \%$ of trade under free trade agreements. In 2012, Mexico formally joined the Trans-Pacific Partnership negotiations and formed the Pacific Alliance with Peru, Colombia and Chile" (CIA, 2016).
} 
Brasil $^{2}$, Colombia ${ }^{3}$ y Argentina ${ }^{4}$. No solo están dos de los países más grandes en términos de extensión, sino también líderes económicos con importantes avances en términos de organización social. De suyo, con ello se parte del reconocimiento propio como actores o agentes ${ }^{5}$, que es la denominación que aquí se seguirá usando.

Lo que es casi un hecho es que, como agente de desarrollo, la sociedad civil sigue siendo invisibilizada tanto por el sector público como por el mercado, pero los discursos oficiales de ambos sectores reconocen las narrativas que marcan transformaciones en medio ambiente y en las violencias basadas en género. Un contrasentido, puede advertir el lector desprevenido. Ello justifica por qué el mayor desafío es lograr que públicos y privados reconozcan la oferta de valor de las osc y, mancomunadamente, construyan ambientes habilitantes.

Es importante recalcar cómo las osc han logrado que se reconozcan sus narrativas y se trabaje en conjunto para alcanzar objetivos comunes. Caso puntual es el interés que tiene la Unión Europea (UE) por la lucha contra las violencias basadas en género en Latinoamérica, sin desconocer los aportes desde las Naciones Unidas. Desde 2006, la ue ha establecido un diálogo birregional junto con la Comunidad de Estados Latinoamericanos y el Caribe (CELAC), para trabajar asuntos en materia de

2 Si bien Brasil se ha caracterizado por ser una "large and well-developed agricultural, mining, manufacturing, and service sectors, and a rapidly expanding middle class" (CIA, 2016), al momento de escribir este artículo, Brasil enfrentaba una situación crisis en términos políticos, económicos y sociales ante la investigación (impeachment) que se llevaba a cabo a la presidenta Dilma Rousseff. "Los expertos prevén que el PIB brasileño retrocederá 3,45 \% en 2016, lo que marcaría la primera vez que el país pasa dos años consecutivos de recesión desde 1930-31, cuando el mundo sentía los efectos de la Gran Depresión” (ввс Mundo, 2016). En los medios de comunicación hay registros de las investigaciones que se adelantan por los niveles de corrupción en empresas estatales como Petrobras. De un lado se hacen cuestionamientos en la búsqueda de transparencia, pero del otro se reconocen los adelantos en términos de equidad en las administraciones a cargo del Partido de los Trabajadores (Luiz Inácio "Lula" da Silva y Dilma Rousseff).

3 “Colombia's consistently sound economic policies and aggressive promotion of free trade agreements in recent years have bolstered its ability to weather external shocks. Colombia depends heavily on energy and mining exports, making it vulnerable to a drop in commodity prices. Colombia is the world's fourth largest coal exporter and Latin America's fourth largest oil producer. Economic development is stymied by inadequate infrastructure, inequality, poverty, narcotrafficking and an uncertain security situation" (CIA, 2016).

4 En diciembre de 2015 tomó posesión el electo presidente, Mauricio Macri. Según Arturo Solís, los cuatro retos para la administración de la Argentina son: la disputa legal con los fondos buitre, un tipo de cambio único, divulgar estadísticas creíbles sobre el estado de la economía y, finalmente, atraer la inversión extranjera al país (Revista Forbes, 2015). No obstante, para el World Factbook de la CIA "MACRI has taken significant steps to liberalize the Argentine economy. His administration lifted capital controls; floated the peso, negotiated debt payments with holdout bond creditors, and removed export controls on some commodities" (CIA, 2016).

5 Para los constructivistas, en el marco de las relaciones internacionales, la denominación de agente cobra relevancia en tanto los atributos mismos del agente y las limitaciones del actor. Este solo representa, mientras que aquel supone un grado de influencia decisiva sobre su entorno (Frasson-Quenoz, 2015, p. 48). 
género. La cooperación ofrecida por la UE a los latinoamericanos va desde el apoyo político hasta la ayuda legislativa. Este diálogo ha sido bien recibido por la sociedad civil, pero va más allá porque exige que se tomen medidas concretas para la erradicación del feminicidio, como la creación de indicadores, la definición de mecanismos de evaluación y que, por supuesto, incluya la información y participación de la sociedad civil (AIETI, 2014).

En estos encuentros se ha contado con la participación del Comité de América Latina y el Caribe para la Defensa de los Derechos de la Mujer (CLADEM), que articula organizaciones feministas latinoamericanas como la iniciativa de Copenhague para Centroamérica y México (CIFCA); Fundación Heinrich Böll; Asociación de Investigación y Especialización sobre temas Iberoamericanos (AIETI); Alianza por la Solidaridad, Grupo Sur; Lobby Europeo de Mujeres y Oxfam Intermón (Grupo Sur Red de Incidencia UE-América Latina y el Caribe, 2015), entre otras.

Con tantas organizaciones involucradas, se planteó como objetivo central de este ensayo establecer la oferta de valor que ellas ostentan. Por ello, se escogieron cuatro territorios latinoamericanos, donde las osc tienen dinámicas propias y han logrado incidir en los dos temas de estudio (medio ambiente y violencias basadas en género).
Ello obliga a preguntarse: ¿cuál es la oferta de valor de las organizaciones de la sociedad civil latinoamericana, en el caso concreto, de las de México, Brasil, Colombia y Argentina? La hipótesis de la que se parte es que las OsC de los países estudiados cuentan con conocimientos técnico-legales que les posibilitan desarrollar una serie de estrategias y tácticas (acciones colectivas), y logran robustecer el lenguaje y los códigos civiles y penales ${ }^{6}$. Ellas realizan propuestas alternativas (procedimentales, legales, políticas) para el proceso de toma de decisiones, y cuentan con destrezas para adelantar informes técnicos (científicos, económicos, ambientales, entre otros). En concreto, en la mayoría de los casos cuentan con metodologías o modelamientos técnicos para buscar información o desarrollar trabajo mancomunado, tienen habilidades para desarrollar redes con las que construyen estándares o indicadores; hacen control social y accountability.

Para encontrar las evidencias que posibiliten verificar, negar o modificar la hipótesis planteada, se revisó la información de páginas oficiales en cada uno de los cuatro estados y páginas de las diferentes osc de las que a priori se tenía referente de trabajo en las temáticas escogidas. Ello como información de primera mano. Luego, se recurrió a la información de los principales medios de comunicación de

6 El término "genocidio" es un desarrollo de las ong de derechos humanos. De manera puntual, lo desarrolló Raphael Lemkin, quien en 1944 publicó un libro acuñando el término para la política de matanza racial de los nazis. De otro lado, se tiene el término "feminicidio", desarrollado por la escritora Carol Orlock, en 1974, y utilizado públicamente por la feminista Diana Russell en 1976, ante el Tribunal Internacional de los Crímenes contra las Mujeres, en Bruselas. 
cada uno de los países, como información secundaria. De esta manera, con la evidencia recolectada, se elaboró una matriz (ver figura 1A y 1B) para visualizar hechos (según cada caso), alcances (éxitos sustanciales o procedimentales) y desafíos (observaciones) de las acciones que pudieran caracterizarse como oferta de valor propia o compartida.
Como se ve en las figuras (1A y 1B), el eje estuvo guiado por la categorización de Gamson (1990 y 2003), retomada por Miguel Armando López Leyva (2012). De esta manera, se identificaron los éxitos procedimentales y sustanciales ${ }^{7}$ que posibilitan establecer la existencia concreta de una oferta de valor. No sin antes hacer una revisión documental sobre el concepto central de este artículo: oferta de

FIGURA 1A. MATRIZ DE REGISTRO DE CASOS DE MEDIO AMBIENTE

\begin{tabular}{|c|c|c|c|c|}
\hline \multicolumn{2}{|c|}{ Objetivo: identificar los casos de medio ambiente en los cuatro casos de estudio, en lo corrido del siglo XXI. } \\
\hline & Caso & $\begin{array}{c}\text { Éxito } \\
\text { sustancial }\end{array}$ & $\begin{array}{c}\text { Éxito } \\
\text { procedimental }\end{array}$ & Observaciones \\
\hline México & & & & \\
\hline Brasil & & & & \\
\hline Colombia & & & & \\
\hline Argentina & & & & \\
\hline
\end{tabular}

Fuente: elaboración de las autoras.

FIGURA 1B. MATRIZ DE REGISTRO DE CASOS DE VIOLENCIAS BASADAS EN GÉNERO

\begin{tabular}{|c|c|c|c|c|}
\hline \multicolumn{5}{|c|}{ Objetivo: identificar los casos de violencias de género en los cuatro casos de estudio, en lo corrido del siglo XXI. } \\
\hline & Caso & Éxito sustancial & Éxito procedimental & Observaciones \\
\hline México & & & & \\
\hline Brasil & & & & \\
\hline Colombia & & & & \\
\hline Argentina & & & & \\
\hline
\end{tabular}

Fuente: elaboración de las autoras.

El éxito procedimental consiste en la apertura de canales de participación y su reconocimiento como representantes legítimos de las demandas. El éxito sustancial consiste en cambios en la política pública o normatividad derivados de los reclamos de las organizaciones (López Leyva, 2012, p. 171). 
valor (huelga anotar que este concepto está en construcción). Para efectos de concisión, en este artículo, solo le presentan los resultados relevantes que la matriz posibilitó visibilizar.

\section{LOS CONCEPTOS PARA AVANZAR}

La fuerza de las osc es de vieja data. Basta volver la mirada a comienzos del siglo xx para encontrar que el accionar de estas organizaciones es tan grande que logra revoluciones. En concreto, los aztecas hicieron la Revolución mexicana. Definitivamente, una muestra de cómo las organizaciones reaccionan ante la vulneración de sus derechos.

En realidad, las acciones de las osc cobran importancia al momento de la consolidación de sociedades más incluyentes y activas. De hecho, en América Latina, ellas también reivindican sus derechos en una gran variedad de temáticas. En este artículo se analizarán las acciones dirigidas a la protección del medio ambiente y las que focalizan las violencias contra la mujer, basadas en derechos humanos; esto, por un lado, en razón a que los gobiernos han elegido la explotación de minerales como el eje fundamental para lograr un desarrollo (centrándose en lo económico) y, por ende, se ha vulnerado el ambiente. Del otro lado, porque en lo corrido del presente siglo, los países latinoamericanos experimentaron dificultades para garantizar los derechos de las personas.

De esta manera, se empezará por establecer un marco que permita una aproximación a la conceptualización de sociedad civil, cultura de desarrollo, desarrollo y oferta de valor. Luego, en cada caso de estudio se analizarán sus estrategias para no solo dejar huella, sino para ser agentes de cambio. Es ahí donde se identificará la oferta de valor que manejan.

No es un secreto que, en el ámbito internacional, la reflexión es más que urgente, justo en la coyuntura de las apuestas del siglo XXI. La primera de ellas es la Agenda 2030, que involucra los Objetivos de Desarrollo Sostenible, ya planteados en Río+20; por eso, con los temas ambientales, con los del desarrollo (incluida la inquietud de repensar el paradigma imperante), también se ha entrado en la necesidad de repensar y reconocer a las osc. Ellas, que están presentes en el territorio, que le apuestan al juego democrático, que hacen tejido con los poderes económicos y políticos; ellas, como sujeto, tienen una oferta de valor. Y entenderla es una tarea pendiente.

Si bien para algunos autores, sociedad civil es un concepto operativo (Maldonado, 2002), en realidad es un concepto en construcción permanente. Viene desde los griegos clásicos, se transforma en el siglo XVIII, y a partir de finales del siglo xx recobra importancia.

Hoy hay mayores desarrollos académicos desde las relaciones internacionales. En este artículo se retoma la apuesta de Mary Kaldor (2005), donde el agente tiene un rol y, simultáneamente, es un medio para meditar, comentar y negociar; el término de sociedad civil global también ha sido usado por José Vidal Beneyto (2003), John Keane (2009), entre otros. Se abre como espacio sin dejar de ser agente y, justamente, ese espacio o medio se recobra y se robustece con los planteamientos de Margaret Keck y Kathryn Sikkink (2000), en términos de las redes transnacionales de defensa. Es por esto que aquí se utilizan indistintamente. No obstante, es preciso reco- 
nocer que hay autores como Peter Willetts, quien habla de sociedad civil internacional, u otros, como Josep María Atentas y Esther Vivas que utilizan la expresión "resistencias globales”. Quizá porque sus estudios vienen de la sociología y se focalizan en los movimientos sociales (Atentas y Vivas, 2009).

Existe un amplio debate al momento de responder preguntas como: ¿qué es la sociedad civil?, ¿quiénes la componen? Por ello, es bueno establecer que hay autores que la denominan también como el tercer sector, es el caso de Mario Roitter (2005); un sector que se encuentra en medio del Estado y del mercado y que cuenta con mejores capacidades para atender diferentes necesidades de la sociedad. Y se dice que lo hace de manera eficaz y eficiente.

El primero de los cuatro conceptos claves es el de sociedad civil. Aquí, dentro del amplio abanico de definiciones, nos quedaremos con la conceptualización de Mary Kaldor, para quien es "el medio a través del cual se negocian, comentan y meditan los contratos o pactos sociales entre los individuos y los centros de poder político y económico" (2005, p. 26). Antes se anotó que este concepto se trabajará como sinónimo de redes y ello se plantea por cuanto Naidoo y Tandon se refieren a "una red de asociaciones autónomas que los ciudadanos portadores de derechos y cargados de responsabilidades crean voluntariamente, para ocuparse de problemas compartidos, presentar sus intereses comunes y promover sus aspiraciones colectivas" (Keane, 2009, p. 61). Como quiera que sea, las osc son pilar de la vida democrática de los países a lo largo y ancho del mundo. Son esenciales y, precisa- mente, el ambiente habilitante que se genere dentro de un territorio para que dichas organizaciones tengan pleno accionar denotará el carácter democrático en los países.

Es importante resaltar, para no generar confusiones al lector, que la legitimidad que adquieren las organizaciones de la sociedad civil no puede entenderse como la legitimidad derivada de la representación política en términos estatales (Serrano, 2002, p. 85). Esto porque, como es bien sabido, las osc pertenecen a un tercer sector ubicado entre el Estado y el mercado. Un ámbito diferente pero no ajeno a estos. Recuérdese que la legitimidad de las osc es obtenida por lo que hacen, por su experiencia, y eso es lo que se abordará más adelante: su oferta de valor.

El segundo concepto, cultura de desarrollo, viene atado a las osc en la manera que estas, al ser agentes de desarrollo, han inculcado en las sociedades el interés por ser partícipes de las respuestas a las problemáticas latentes en cada territorio. Esa participación generada por la cultura de desarrollo, que ellas han implementado, solo es posible cuando las organizaciones cuentan con una oferta de valor para presentar propuestas y proyectos. Los planteamientos de las osc tienden a ser más robustos no solo por la investigación en sí misma sino por la fortaleza de la cohesión social. Ya lo anotaba Boisier (1995), cuando mencionaba que entre mayor tejido social exista, mayor será la propensión a generar una cultura de desarrollo.

Hasta ahora se han mencionado dos conceptos. El tercero puede resultar controvertido, por eso aquí se quiere hacer referencia a la transformación del desarrollo. De un lado se 
tiene la conceptualización clásica ${ }^{8}$ que tiene antecedentes "vinculados con un modelo de desarrollo cuyo objeto es superar el retraso imperante desde la Segunda Guerra Mundial, caracterizado por un crecimiento económico basado en la evolución del producto nacional bruto y en el ingreso por habitante" (CEPAL, s.f., p. 21).

Derivada de ella, aparece el desarrollo sostenible como "un proceso político y social que abarca todos los aspectos de la vida, en forma armoniosa y equilibrada con la conservación del medio ambiente y los recursos naturales, en una concepción tridimensional del desarrollo" (CEPAL, s.f., p. 21).

De los debates globales también surge el desarrollo humano. Un enfoque alternativo que abarca mucho más que la variable económica. De manera precisa, para el Programa de las naciones Unidas para el Desarrollo (PNUD), es "un proceso de expansión de las capacidades de las personas y de las libertades efectivas que ellas experimentan en sus trayectorias de vida" (s.f.). De lo que se habla es de una vida extensa y sana, de educación y de conocimiento; del acceso a los recursos para una vida digna y la potestad de poder asociarse libremente para participar.
Más recientemente, hay quienes hacen referencia al redesarrollo que surge a partir de un desarrollo en contra de aquellos avances que fueron mal diseñados o que se consideran obsoletos. Es un enfoque proveniente del sur, y tiene en cuenta el desarrollo como medio de ajuste de procesos. "Conceptual y políticamente, el redesarrollo se convierte en desarrollo sostenible para nuestro futuro en común, tal como fue prescrito en la Comisión Brundtland. También ha sido promovido como redesarrollo ambiental y democrático" 9 (Esteva, 2010, pp. 12-13) (Traducción de las autoras).

Es importante recalcar que son las osc las que desarrollan una conciencia pública dentro de la sociedad. "Ellas alertan sobre los límites que tiene el desarrollo e incentivan para que se ejerzan controles políticos, en busca de la protección de objetivos comunes. La apuesta es a que la sociedad pueda desarrollar actividades y logre innovar en un contexto social favorable, sin olvidarse de los límites propios del desarrollo" ${ }^{10}$ (traducción de las autoras). Incluso, que las osc sean espacio de discusión es un paso para lograr cambiar el paradigma. Para que se nombre, para que se posibilite una narrativa diferente. Que se generen sis-

8 Fue la que dio lugar a la creación, en 1948, del hoy Banco Mundial y, en 1959, a la creación del Banco Interamericano de Desarrollo (BID). Más tarde se crean bancos regionales y subregionales.

9 "Conceptually and politically, redevelopment is now taking the shape of sustainable development, for 'our common future', as prescribed by the Brundtland Commission. Or else it is being actively promoted as green and democratic redevelopment...” (Esteva, 2010, p. 13).

10 "It pleads, first of all, for political controls to protect those new commons and offer common men a more favourable social context for their activities and innovations. Such political controls can be implemented only after public awareness of the limits of development has become firmly rooted in society...” (Esteva, 2010, p. 20). 
temas de previsión, prevención y control y, si es necesario, sistemas de restauración (Marín Aranguren, 2016, p. 543).

El cuarto concepto tiende a generar mayor ruido. Ya anotábamos que no hay un gran acervo de literatura sobre oferta de valor. No obstante, sí puede anotarse que esta se basa en los Principios de Estambul ${ }^{11}$, establecidos en el Open Forum ${ }^{12}$.

Para la Confederación Colombiana de ONG (CCONG, 2016), la oferta de valor puede ser definida como aquellas fortalezas que les permiten a las osc potencializar su papel como agentes de desarrollo. Hoy se sabe que demostrar esta oferta de valor puede contribuir con su propia sostenibilidad en el tiempo. Vistas desde la perspectiva de agentes de desarrollo, las osc contribuyen al establecimiento de un diálogo público que incide en el ciclo de las políticas públicas. También generan nuevo conocimiento que permite brindar mejores servicios y beneficios. Y esto es, precisamente, lo que les otorga gran legitimidad a las organizaciones. En estos términos, esa legitimidad técnica, legal o moral es difícilmente cuestionable $^{13}$. Lo concreto es que el trabajo de las osc va más allá de un carácter asistencial y compensatorio, desarrollan proyectos productivos y sostenibles (Serrano, 2002, p. 77), con herramientas, pedagogías y metodologías que hacen parte de esa oferta de valor propia de este agente que también desarrolla innovación.

Es así como el accionar de las osc genera una relación de corresponsabilidad en donde, en la interacción del binomio poblaciónorganización, se descubre la oferta de valor que es inigualable $y$, de manera singular, ha podido brindar soluciones efectivas mediante su incorporación en el ciclo de las políticas públicas (puesta del tema en la agenda, desarrollo normativo-político de la decisión, implementación y, en algunas ocasiones, evaluación) dando respuesta a las necesidades de la población. Quizá por ello, las comunidades tienden a organizarse e integrarse con diversos pares sociales para exigir y garantizar que se cumplan sus derechos.

Existen, entonces, tres características exclusivas: valor, diferenciación y relevancia.

11 Son los que guían el trabajo y las prácticas de las osc, tanto en contexto de paz como en el de conflicto, y van desde las emergencias humanitarias hasta las acciones de desarrollo a largo plazo.

12 Establecidos el 29 de septiembre de 2010, en Turquía.

13 El secretario general de Civicus reconoce que a las organizaciones se les imputan cinco mitos, pero es preciso analizar cada caso porque "en primer lugar, los modelos de financiamiento han estado dirigidos a las grandes organizaciones del norte, haciendo que estas sean cada vez más grandes y tengan mayor capacidad de acción mientras que las organizaciones del sur no logran obtener esos montos en recursos de ayuda; causando así desequilibrios. En segundo lugar, la gran concentración y control de los recursos por organizaciones del norte ha llevado a que las del sur no tengan guías de asociación ni códigos de conducta que involucre a la población local en el diseño y ejecución de sus programas. En tercer lugar, existe una fuga de personal de organizaciones locales a internacionales con un atractivo salarial imposible de alcanzar en el territorio, esto debilita el desarrollo de las locales. Cuarto, el afán por recaudar mayores fondos para la financiación de las organizaciones ha disminuido la transparencia de donantes generando problemas éticos. Finalmente, las organizaciones se están involucrando cada vez más con las economías políticas en las que operan, dejando a un lado la confrontación en contra de estas” (Sriskandarajah, 2016). 
Esas características las diferencian del Estado y del mercado.

El valor hace referencia al cumplimiento de los protocolos y de los estándares de calidad al momento de ofrecer los diferentes servicios, bienes y productos; estos se acompańan de estrategias que generan competencias sociales y ciudadanas; posibilitan la construcción de acuerdos y pactos; incorporan la perspectiva de géneros y respeto a la diversidad; y son respetuosos del ambiente.

La diferenciación establece que todos los servicios, bienes y productos que se ofrecen, se basan en la adopción de buenas prácticas de autorregulación, transparencia y rendición pública de cuentas; además, estas promueven la innovación social y la construcción de pedagogías, metodologías y nuevo conocimiento, para el mejoramiento de las condiciones, y el fortalecimiento de las capacidades ciudadanas para ejercer su papel social y político.

Por último, está la relevancia que se le da a la participación activa y responsable del sector, en la construcción, ejecución, seguimiento y control social a las políticas públicas, y la promoción de escenarios de diálogo político, con el propósito de incidir en las decisiones para resolver las problemáticas de pobreza, exclusión y guerra (CCONG, 2016).

Hay que dejar claro que la oferta de valor de cada una de las osc latinoamericanas no es homogénea. Siempre dependerá de sus propias prácticas y de las temáticas en las que esté involucrada. Incluso, puede decirse que hay prácticas y metodologías que son usadas de manera reiterada porque son exitosas, pero siempre requieren ajustes locales que hacen parte del proceso de apropiación del nuevo conocimiento.

\section{CASO A CASO EN MEDIO AMBIENTE}

Los países latinoamericanos se han caracterizado por adoptar la extracción de recursos naturales como uno de los medios idóneos para generar mayor desarrollo y crecimiento económico. Sin embargo, como se mencionó, el desarrollo de hoy en día viene atado a unos límites para permitir la sostenibilidad del medio ambiente y así proteger los recursos para las generaciones futuras. Estos procesos extractivos, junto con la construcción de obras de infraestructura, han vulnerado el derecho de los ciudadanos a vivir en un ambiente sano. El medio ambiente no se ha protegido de manera sostenible. En algunos casos, se saltan procesos de concertación. Un ejemplo de esto es lo ocurrido entre el pueblo indígena kichwa de Sarayaku y el Gobierno de Ecuador; este último adjudicó títulos de exploración de hidrocarburos y explotación de petróleo en zonas pertenecientes a la comunidad indígena sin consultar previamente a los habitantes ${ }^{14}$.

El lector atento notará que el ejemplo no se circunscribe al estudio de caso, pero es una constante en la región. El Instituto Latinoamericano para una Sociedad y un Derecho Alternativos (ILSA) hace seguimiento a la vulneración del derecho a la consulta previa

14 Finalmente, la Corte Interamericana de Derechos Humanos declaró al Gobierno de Ecuador culpable de la violación del derecho de consulta de los pueblos (Corte Interamericana de Derechos Humanos, 2012). 
$y$, en Colombia, los estudios de la investigadora Gloria Amparo Rodríguez, en términos de la misma violación, son reconocidos en el mundo ${ }^{15}$.

De manera concreta, osc y miembros de la comunidad académica hacen seguimiento y elaboran informes para que se tomen decisiones legales ante el incumplimiento de los compromisos internacionales, como el Convenio 169 de la Organización Internacional de Trabajo (отт). Este es el tratado internacional que obliga a la consulta previa; por eso los diferentes componentes de la sociedad civil juegan un papel importante en la divulgación de la información y en el conocimiento de la normatividad internacional y local que debe respetarse.

Es así como a raíz de su interés en denunciar amenazas al medio ambiente, a través del conocimiento que elaboran y divulgan, producen informes para también sensibilizar a la población. Muestra de ello es la publicación del informe "Última frontera: políticas públicas, impactos y resistencias al fracking en América Latina”, elaborado por Censat Agua Viva, Ambiente y Sociedad, Red de Justicia Ambiental, entre otras, para que población y tomadores de decisión conozcan la urgencia de repensar el modelo energético en el subcontinente (Contagio Radio, 2016).
Una característica común en Latinoamérica es que internacionalmente aparentan probidad jurídica en términos ambientales, pero no son próvidos en la definición de políticas transversales. Por un lado, generan normatividad para protegerlo; pero por el otro, otorgan el aval a megaproyectos que ponen en riesgo el medio ambiente. Eso es lo que sucede en México, Brasil, Colombia y Argentina.

\section{MÉxICO}

En este caso, en la entrada a América Latina, en el país azteca cabe destacar que las osc tienen fuerza desde mucho antes del periodo de estudio (2000-2016). A raíz de la firma del Tratado de Libre Comercio de América del Norte (TClan) en 1992, por ejemplo, surgen organizaciones como el Movimiento Ecologista de Sonora y la Red Fronteriza de Salud y Ambiente para sensibilizar sobre los posibles efectos que causaría este tratado sobre los ecosistemas en la región fronteriza (Lutz Ley y Salazar, 2011). Ahora, entrada ya más de una década del siglo XXI, las organizaciones mexicanas se han destacado por su accionar frente a la gran minería y las gestiones ante el Estado y las empresas nacionales o extranjeras que comprometen la calidad ambiental del territorio. Ellas hacen accountability social ${ }^{16}$

\footnotetext{
15 Al respecto se puede ampliar en "Consulta Previa: la punta del iceberg de los dilemas sociales frente a la extracción de recursos naturales en Colombia” (Marín Aranguren, 2013).

16 El accountability social es un mecanismo de control horizontal de las autoridades políticas basado en las acciones de un amplio espectro de asociaciones y movimientos ciudadanos, así como en acciones mediáticas. El objetivo es monitorear el comportamiento de los funcionarios públicos, exponer y denunciar actos ilegales de los mismos, y activar la operación de agencias horizontales de control (Peruzzotti y Smulovitz, 2002).
} 
y logran movilizar, más que a activistas, a ciudadanos interesados en proteger el medio ambiente, también involucran a los medios de comunicación y-cuando es el caso-llegan a los estrados judiciales, para que se apliquen las normas y se protejan los recursos naturales.

La capacidad de acción de las osc se resalta en cada uno de los siguientes casos donde trabajan en la protección del medio ambiente. Uno de los mecanismos más usados por las organizaciones es la recolección de firmas para revocar decisiones. En septiembre 24 de 2015, la Secretaría de Medio Ambiente y Recursos Naturales (SEMARNAT) otorgó una licencia para la construcción de un proyecto que buscaría extraer roca basáltica en la Reserva de los tuxtlas, en el estado de Veracruz. Ante esta notificación, organizaciones como el Centro Mexicano de Derecho Ambiental (CEDAM), Resistencia Organizada para la Conservación Ambiental (La Roca), la Asociación Interamericana para la Defensa del Ambiente (AIDA), y la Asamblea Veracruzana de Iniciativas y Defensa Ambiental (LAvida) recolectaron 37.536 firmas en la plataforma Change.org para revocar la autorización de extracción de roca en dicha reserva. Ello con el objeto de ampliar el puerto de Veracruz (CEDAM, 2015). En este caso, simplemente funcionó como una alarma de alerta porque hicieron falta 12.464 firmas, frente a las 50 mil requeridas (Change, s.f.), pero hoy hay mayor conciencia del daño ambiental; por ejemplo, se sabe que con la ampliación del puerto hay mayor riesgo de infringir el Convenio Ramsar, ratificado por México en 1986 y, que al extraer la roca basáltica no solo se pone en peligro la reserva natural de los tuxtlas, sino también al mono aullador, una especie en vía de extinción, según la norma Nom059.

La movilización es otra de las acciones colectivas propias de las osc para reivindicar sus derechos. A ella se recurrió para detener la explotación de minerales. Caso ejemplar se dio en Cocula, estado de Guerrero, en donde la población de la región de Nuevo Balsas ha realizado acciones colectivas informales, como bloqueos, tanto a la entrada a la mina, en el cerro La Joya, como en sus vías de acceso. La población reivindica su derecho a vivir en un medio ambiente sano, y por eso se opone a la extracción de oro, que contamina sus cuerpos de agua. El debate se centra en que por un lado está la minería y por otro la vocación de la población que vive de la pesca. Los habitantes de Cocula denuncian la contaminación producida por la explotación (No a la Mina, 2016). Por ello, los líderes de Nuevo Balsas han tenido reuniones con el gobernador del estado de Guerrero ${ }^{17}$. La Red Mexicana de Afectados por la Minería ha emitido comunicados al respecto, en donde establece que "demostrar que no existen dańos por la explotación minera es difícil, por esto mismo se solicita a los

17 El 5 de abril de 2016 se reunieron con Héctor Astudillo Flores, gobernador del estado de Guerrero, quien insistió en que no existen dańos ambientales a consecuencia de la explotación que se está llevando a cabo en el cerro La Joya. 
gobernantes no hacer afirmaciones sin tener conocimiento pleno del tema" 18 .

Otro caso que cabe destacar es Pronatura. Esta organización ambiental incentiva la responsabilidad social empresarial, en términos de protección ambiental. En 2008 instauraron el programa Neutralízate, que cuenta con tres pasos para mitigar el impacto: el primero busca cuantificar la emisión de gases efecto invernadero y así elaborar una radiografía de la empresa. El segundo identifica las medidas exitosas, en términos de reducción de emisiones, y el tercero, a través de proyectos forestales, busca compensar las emisiones. Por medio de este tipo de programas se buscan alianzas como la realizada por Pronatura con la farmacéutica Chenoin (Corresponsables México, 2016).

El conocimiento técnico y legal que poseen las organizaciones es uno de los estandartes que permite fortalecer la oferta de valor. La elaboración de informes evidencia su papel como agentes robustos para el desarrollo. En México, organizaciones de la sociedad civil $^{19}$, dedicadas a la protección ambiental y la diversidad del país, enviaron un documento de soporte a la Secretaría de Medio Ambiente y Recursos Naturales (sEMARNAT) y a la Comisión Nacional de Áreas Naturales Protegidas (CONANP), para ser integrado a los estudios previos para la creación del Área Natural Protegida (ANP), Reserva de la Biosfera Caribe Mexicano (RBCM), en el estado de Quintana Roo. El proceso de creación de esta zona se verá fortalecido si se incluye a las comunidades directamente beneficiadas o afectadas por el proyecto. Las organizaciones actualmente adelantan talleres de sensibilización para que se incremente la participación (CEDAM, 2016).

Es con lenguaje e información apropiada para cada público como las osc logran sensibilizar a la población. Les informan de los efectos de los diversos proyectos mineros que se adelantan en el país. Las más de veinte osc recurren a diversas plataformas virtuales para informar y para facilitar la recolección de firmas. Trabajan mancomunadamente para recordarle a las diferentes entidades estatales su compromiso con la preservación del medio ambiente y la imperiosa necesidad de proteger a las comunidades locales. Y por ello muchas trabajan en el fortalecimiento de procesos de participación ciudadana, de modo que se logre la previsión, prevención y control de los proyectos; siempre mitigando los conflictos.

\footnotetext{
18 Comunicado del 5 de abril de 2016 de la Red Mexicana de Afectados por la Minería (REMA). Recuperado de http://www.remamx.org/comunicado-enviado-al-gobierno-del-estado-de-guerrero/

19 Alianza Kanan Kay, Alma Verde Holbox, Amigos de Isla Contoy A.c., Amigos de Sian Ka’an A.C., Asociación de Prestadores de Servicios Acuáticos de la Riviera Maya A.C. (ApsA), Blue Core A.C., Casa Wayuu A.C., Centro Ecológico Akumal (CEA), Centro Mexicano de Derecho Ambiental A.c. (CEmDA), Centinelas del Agua A.C., Ch’ooj Ajauil A.C., Colectividad Razonatura, Comunidad y Biodiversidad A.C. (сові); Flora, Fauna y Cultura de México A.C., Grupo Tortuguero del Caribe A.c., Iniciativa Arrecifes Saludables (Hri), Manatus México, Ocean Solutions México, Onca Maya A.c., Organización Mexicana para la Conservación del Medio Ambiente A.c. (omca), Reserva Ecológica El Edén A.c., Saving Our Sharks A.c. (sos), Voces Unidas de Puerto Morelos (cedam, 2016).
} 


\section{BRASIL}

Cuando se piensa en medio ambiente y en Brasil, quizá lo primero que el lector recuerde es que, como Colombia, es un país megadiverso (Gómez Lee, 2005). En uno y otro territorio se extiende la selva amazónica. Otros podrán recordar a uno de los activistas más importantes, en términos de bosques y cambio climático: Chico Mendes, el primer latinoamericano que, desde una osc, habló en el seno de las ONU. Brasil también recurre al modelo de neoextractivista.

Esa historia hace que las osc brasileñas sigan siendo innovadoras en acciones colectivas y alerten sobre problemáticas ambientales que se viven en sus territorios. Usan la alegría del carnaval más famoso del mundo para protestar. En otros casos, ellas apoyan a las comunidades y alertan sobre consecuencias por intervenciones minero-energéticas $y$, en muchos casos, terminan siendo criminalizadas ${ }^{20}$. Más allá de estar centradas solo en los seres humanos, las organizaciones también protegen especies que están en vía de extinción, como es el caso de la tortuga do Paraíba.

En 2011, Greenpeace Brasil realizó una protesta, en Río de Janeiro, en contra de la explotación petrolera del grupo empresarial EBX. Los manifestantes se disfrazaron de balle- nas y usaron máscaras con la cara del entonces presidente del grupo empresarial: Eike Batista. Según Greenpeace, las exploraciones cercanas al Parque Nacional Marino de Abrolhos afectaban a las ballenas jorobadas. Ellos lograron que, para agosto de 2011, más de 13.000 activistas enviaran cartas solicitando la expulsión de los bloques de exploración. Luego de no recibir respuesta, ellos dieron cuenta de la poca transparencia en la prensa (Periódico Estadao, 2011). Sin duda, la creatividad no solo es para conseguir objetivos sino también para concientizar a la población.

No obstante, a la hora de ejecutar proyectos de explotación minera, los gobiernos siguen dejando a un lado a las comunidades. Esto fue lo que sucedió a finales de 2015, en Mariana, estado de Minas Gerais, cuando una avalancha de residuos tóxicos ${ }^{21}$ arrasó con el pueblo entero. Causó la muerte de 19 personas y provocó graves dańos sociales, económicos y ambientales. Algo que el Instituto Socioambiental (ISA) y varias Osc brasileñas habían denunciado al inicio del proyecto (No a la Mina, 2016). El Movimiento de Afectados por las Represas, junto con Articulación Internacional de Afectados y Afectadas por la Vale realizaron protestas durante el proceso de adjudicación; sin embargo, nunca fueron escuchados y, al contrario fueron estigmatizados (Álvarez, 2016). Esto demuestra que las OsC

20 Caso de Chico Mendes, sindicalista y activista ambiental brasilero, que se convirtió en el impulsor de la defensa de la Amazonia y promotor de la Alianza de los Pueblos de la Selva. Fue acusado de tener vínculos con una organización comunista. Finalmente, fue asesinado a manos del terrateniente Darly Alves de Silva y su hijo, Darcy Alves Pereira, en diciembre de 1988 (Ecologistas en acción, 2015).

21 Provenientes del consorcio Samarco-Vale-BHP, dedicadas a la explotación minera en la cuenca del Rio Doce. 
logran tener prospectiva, que es indispensable cuando de proyectos de intervención se trata, pero que son invisibilizadas y criminalizadas. Con ello, su legitimidad técnica sobresale y su oferta de valor se pone de relieve.

Si bien los casos son innumerables, aquí se quiere resaltar los resultados del trabajo en red. Por ejemplo, desde el 2008, el Centro Nacional de Investigación y Conservación de los Reptiles y Anfibios, adscrito al Instituto Chico Mendes de Conservación de la Biodiversidad y la Fundación Biodiversitas, realizó una serie de informes sobre la tortuga do Paraíba ${ }^{22}$, que luego fue presentada en la Alianza para la Conservación de la Tortuga (TSA), en 2015 (Instituto Chico Mendes de Conservación de la Biodiversidad, 2016). Los alarmantes resultados del informe llevaron a que Wildlife Conservation Society (wcs) y Turtle Survival Alliance, se interesaran en buscar alternativas para esta especie acuática en vía de extinción. Las organizaciones internacionales no solo compraron los terrenos para construir una reserva a orillas del río Carangola, en Tomas, en Minas Gerais, sino que incentivaron el desarrollo de alianzas con los pescadores de la región. En mayo de 2016, se constituyó la reserva para proteger a la tortuga do Paraíba. Como decía Fernando Henrique Cardoso, la legitimidad de las osc debe medirse por lo que hacen, y aquí queda demostrado que las acciones no solo se limitan a las de reivindicación, sino que van más allá con investigación, desarrollo e innovación para la preservación de la vida en el planeta.

Así las cosas, lo que demuestran las organizaciones escogidas para visibilizar el trabajo en favor del medio ambiente en Brasil es que, si bien las acciones colectivas no siempre logran los efectos deseados, sea porque los Estados las criminalizan o porque son invisibilizados, las osc desarrollan metodologías que permiten conocer mejor la flora y la fauna, y logran prever efectos no deseables en los territorios. También se evidencia que las organizaciones tienen la capacidad para establecer alianzas con diferentes comunidades, para generar mayor conocimiento y establecer alternativas que den solución a problemas que han sido creados por la intervención descontrolada de las empresas o del mismo hombre.

\section{Colombia}

Otro país megadiverso es Colombia. Comparte buena parte de la Amazonia y también le apuesta al desarrollo a través de la exportación de commodities. Sin duda, como en muchos casos en Latinoamérica, los conflictos ambientales y sociales se han multiplicado en razón de la intensidad de la explotación mineroenergética. Desde la entrada del siglo Xxi, el país se consagró a la vocación minera, y, desde entonces, el timón está en esa locomotora.

En el caso colombiano ha sido más que necesario el accionar de las osc para impedir

22 Una de las 25 especies de tortugas más amenazadas en todo el planeta (Instituto Chico Mendes de Conservación de la Biodiversidad, 2016). 
normas y decisiones de política que pueden llegar a entorpecer el medio ambiente ${ }^{23}$, así como para lograr la revocatoria de licencias de exploración y explotación, y proteger las zonas caracterizadas por su gran diversidad. Este es el caso del río de los cinco colores: Caño Cristales. Las osc de la región participaron en las audiencias públicas a las que convocó la Corporación para el Desarrollo Sostenible del Área de Manejo Especial La Macarena (Cormacarena). Este es el mecanismo con el que la Corporación Autónoma Regional busca involucrar a las osc a fin de debatir los proyectos para la región ${ }^{24}$; por ello, en 2008, cuando Hupecol se interesó en la exploración petrolera cerca al Parque Natural Tinigua, todas las OsC activaron sus sistemas de alerta al ver amenazado Caño Cristales. No obstante, la Agencia Nacional de Licencias Ambientales (ANLA), en 2016, solo con un estudio presentado por la misma compañía otorgó la licencia. La polémica no se hizo esperar pues ello implicaba exploración en 150 pozos en la zona (Caracol Radio, 2016). Rápidamente, Cormacarena presentó los informes construidos participativamente $y$, ante las evidencias de impacto negativo, la ANLA revocó la decisión. De esta manera, la red de organizaciones logra preservar la diversidad y proteger el medio ambiente (Semana Sostenible, 2016). Ello como consecuencia del principio de precaución contemplado en el artículo 1 de la Ley 99 de 1993. No se olvide que esta norma reconoce a las osc como agentes del Sistema Nacional Ambiental (sInA).

Otro gran revés de la locomotora minera del actual presidente Juan Manuel Santos está relacionado con el cumplimiento del Convenio 169 de la огт: la Consulta Previa, que en un gran número de casos ha sido ignorada. Por ello, organizaciones como el Centro de Estudios para la Justicia Social Tierra Digna (2016) han decidido la vía judicial para evitar la vulneración de ese derecho. La consulta previa ha de ser abierta, libre e informada. Tierra Digna, recurriendo a la tutela, alegó los derechos a la alimentación, el acceso al agua, al medio ambiente sano y al patrimonio cultural, que fueron vulnerados. Por tales motivos, la Corte Constitucional, en su sentencia T-766 de 2015, dejó sin efecto tres resoluciones ${ }^{25}$ que demarcan las denominadas Áreas de Reserva Estratégica Minera en la Amazonia, la Orinoquia, el Chocó Biogeográfico y el Macizo colombiano, que el Gobierno había demarcado como potencialmente explotables, pero que comprometían la biodiversidad ( $E l$ Espectador, 2016).

23 Es el caso de la Ley de Bosques que por varios años se intentó normar pero que la acción de las osc posibilitó la declaración de constitucionalidad y por ende la sanción del presidente de la república.

24 Ejemplo de esto es la audiencia realizada el 21 de abril en la ciudad de Villavicencio para presentar el Plan de Acción Institucional, vigencia 2016-2019, a esta audiencia se convocaron los representantes de los sectores públicos, privados, gremios, ONG ambientales, organizaciones no gubernamentales, entes de control y la comunidad en general.

25 Resoluciones 180241 y 0045 de 2012 proferidas por el Ministerio de Minas y Energía, y la Resolución 429 de 2013 de la Agencia Nacional de Minería. 
Recurrir a los estrados judiciales para obtener logros en términos de derechos es una práctica cada vez más recurrente en América Latina. Algunos autores hablan de los peligros de esta judicialización, pero las Entidades sin Ánimo de Lucro (eSAL) lo que buscan es la protección de derechos y usan las herramientas disponibles en la ley.

Otra estrategia usada por las organizaciones para cuidar el medio ambiente son las redes. Con ellas se logra identificar los conflictos ambientales en el mundo para crear conciencia de los impactos tanto en el Estado, las empresas y la sociedad. Lo que quieren es empoderar a las comunidades afectadas como baluarte de la sostenibilidad ambiental y copartícipes de la responsabilidad social. Este es el caso de la alianza entre el Instituto Cinara, de la Universidad del Valle, con el Environmental Justice Organisations Liabilities and Trade, con el que desarrollarán el Atlas Global de Justicia Ambiental ${ }^{26}$. Al proyecto se unen otras organizaciones como Censat Agua Viva y el Observatorio de Conflictos Mineros de América Latina (ocmal). Se crean redes donde no solo se genera nuevo conocimiento, sino que permiten la interacción multiactor en diferentes ámbitos (local, nacional e internacionalmente).

Para los académicos de la Universidad del Valle la sociedad es vista como un proceso metabólico que crece movido por tres grandes motores: los aumentos de la población, del consumo y de la producción. "Al crecer este metabolismo, también crece la demanda por los recursos naturales y se aumenta la contaminación, generando así conflictos ambientales" (Universidad del Valle, 2015). Y según la misma universidad, tanto la minería legal como ilegal son los primeros generadores de los conflictos socioambientales en Colombia, seguido por las actividades de combustibles fósiles, hidroeléctricas y agroindustrias (Universidad del Valle, 2015). En el mapa de ocmal Colombia ya aparecía con una alta incidencia de conflictos ambientales entre los países latinoamericanos, pero con esta red la información será más robusta y se convertirá en un referente de consulta.

Es recurrente que se identifique a Colombia como un país con un legado normativo amplio e interesante ${ }^{27}$, como también que las normas se quedan en el papel. Sin embargo, las OsC no solo conocen la jurisprudencia internacional y nacional, sino que apelan a ella para conservar el medio ambiente y proteger sus derechos. Aquí queda demostrado cómo la destreza legal y técnica que ellas manejan les permite conocer los mecanismos y las herramientas para participar y ser exitosas en sus demandas. También, cómo algunas se convierten en referente informativo.

En realidad, logran resultados procedimentales como la realización de audiencias públicas y éxitos sustanciales como la revocatoria de licencias ambientales. El uso de

\footnotetext{
26 Mapa que busca ubicar los casos de conflicto en el mundo, un proyecto promovido por la UE.

27 Colombia fue el primer país de América Latina en tener un Ministerio de Medio Ambiente a raíz de la creación del Sistema Nacional Ambiental bajo la Ley 99 de 1993 (Marín, 2009).
} 
instrumentos jurídicos como la tutela y el principio de precaución son herramientas que requieren una destreza que tienen las osc; hacen parte de su oferta de valor. Esa destreza, junto con el conocimiento legal y técnico, les permite generar confianza y así entablar relaciones de corresponsabilidad, algo innato en las osc.

\section{Argentina}

El país gaucho es una de las mayores ecorregiones de América Latina, con una gran variedad que va desde la selva del Paraná e incluye zonas en el Antártico; además, a lo largo del territorio tiene zonas en estado puro. Su gran diversidad se puede evidenciar en el contraste entre el cerro Aconcagua, ubicado en la provincia de Mendoza, que es reconocido como la montaña más alta del continente americano. La sima más profunda de todo el continente americano es la Laguna del Carbón, en la provincia de Santa Cruz.

El incumplimiento de las leyes es la denuncia reiterada de las osc. Organizaciones como Greenpeace-Argentina, la Fundación Ambiente y Recursos Naturales (FARN) y la Fundación Vida Silvestre Argentina presentaron denuncias por la falta de cumplimiento a la Ley de Bosques. Estas organizaciones senalaron que "la sanción de la Ley de Bosques significó un avance sin precedentes en materia ambiental [...] y un logro trascendental en la participación de la sociedad civil en el reclamo efectivo de una norma de protección ambiental". No obstante, su implementación efectiva enfrenta severas dificultades (Fundación Vida Silvestre, 2013).
Por esta razón, y gracias al conocimiento técnico de varias osc, se han encendido las alertas en la formulación de los planes de ordenamiento territorial de varias provincias (Formosa y Córdoba), donde se desmontan zonas que habían sido consideradas como zonas de especial protección (Fundación Vida Silvestre, 2013).

Ellas no solo denuncian, sino que concientizan a la población y abren espacios de debate e información para que los habitantes conozcan los efectos de algunas decisiones que se toman en las provincias. Por ejemplo, el pasado 1 de junio de 2016, en Villa Gregoria Matorras, en San Martín, se realizó la conferencia "El glifosato daña". Explicaron los efectos sobre la salud y la biodiversidad; además presentaron argumentos según los cuales el glifosato debería estar prohibido. Los organizadores de esta conferencia fueron: el Foro Ecologista de Paraná, Red Nacional de Acción Ecologista (Renace), la Asamblea Río Cuarto Sin Agrotóxicos, el Instituto de Salud Socioambiental de la Universidad Nacional de Rosario, el Instituto Derecho Ambiental del Colegio de Abogados de Entre Ríos y el Núcleo de Acceso al Conocimiento Paraná (AIM: Agencia de Informaciones Mercosur, 2016).

La participación de las organizaciones en los procesos de elaboración de políticas públicas y leyes ha sido uno de sus grandes aportes. Es su legitimidad técnica la que permite que se incluyan temas nuevos en la agenda. Además de incluir algunas de sus exigencias. Diferentes organizaciones ambientales y cátedras universitarias, entre ellas: Guardianes de Iberá, la Asociación por la Justicia Ambiental (AJAM), el Observatorio del Derecho a la Ciudad (ODC), 
la Cátedra Libre de Ingeniería Comunitaria (UBA), la Cátedra "Seminario Transformaciones y conflictos en el espacio urbano metropolitano de Buenos Aires" (Universidad Nacional de La Plata), el Taller Libre de Proyecto Social (UBA), y la Organización Vecinal Salvemos el Río Gualeguaychú han solicitado la elaboración de un proyecto de ley para la protección y recomposición de los humedales en el país. Según estas organizaciones, los humedales se encuentran afectados debido al mal uso del suelo que se ha cedido para la construcción de inmuebles y para actividades productivas intensivas e invasivas. Efectivamente, las osc hicieron oír sus voces y a través de la Comisión de Recursos Naturales y Conservación del Ambiente, perteneciente a la Cámara de Senadores, se elaboró un Pre Dictamen, incluyendo los lineamientos para la cimentación de un instrumento legislativo que salvaguarde los humedales (Diario Momarandu, 2016). Una vez más se destaca la destreza en lo jurídico y en el cabildeo o lobby.

\section{OFERTAS DE VALOR DE LAS OSC}

La Argentina no escapa al neoextractivismo, $y$, al igual que sus vecinos latinoamericanos, las osc han reivindicado el medio ambiente. Es el caso de los aborígenes en "Las Capillas", quienes han denunciado el despojo de tierras a más de 30 familias de la comunidad. El hecho es que el Gobierno otorgó licencias a la empresa minera Piuqen, en lugares de pastoreo. La líder de la comunidad, Gabriela Flores, no ha obtenido respuestas concretas por parte de las instituciones para detener los despojos; sin embargo, su acercamiento con las instituciones gubernamentales permitió que la comunidad "Las Capillas" obtuviera su personería jurídica. De esta manera puede mejorar su accionar, pues ya se ha consolidado legalmente (No a la Mina, 2016).

En este caso, es importante resaltar que la visibilidad de la organización posibilitó su institucionalización, y este es un paso en la creación de un ambiente habilitante para las osc. Un éxito procedimental (la institucionalización) que le permite participar, de manera formal, en la toma de decisiones. De hecho, la comunidad de "Las Capillas" jugó un rol protagónico en el posicionamiento del despojo, como tema de agenda política y social en ese territorio. Y ahí se convierte en éxito sustancial, a la luz de la teoría usada por López.

Así las cosas, las organizaciones argentinas realizan un accountability social frente a los compromisos que ha adquirido su Gobierno; y también velan por el cumplimiento. Sin duda, su legitimidad técnica y legal posibilita éxitos sustanciales sin considerar por ello que los procedimentales no sean de valor. Lo que se encuentra es que cuentan con estrategias de divulgación e información que las hacen exitosas a la hora de posicionar temas en la agenda, y llegan mucho más allá con sus acciones colectivas.

\section{PASO A PASO POR LAS VIOLENCIAS BASADAS EN GÉNERO}

Después de las dictaduras que sufrió América Latina, a finales del siglo $\mathrm{xx}$, los ciudadanos han demandado la protección de sus derechos, han participado internacionalmente para robustecer la jurisprudencia y para tener 
escenarios de amplia discusión. Incluso, las redes de la sociedad civil han sido baluartes para el establecimiento de órganos como la Corte Penal Internacional o Tribunal Penal Internacional.

No obstante, los Estados latinoamericanos se han quedado cortos al momento de establecer políticas y acciones para evitar las violencias basadas en género, con base en los derechos humanos. Es por esto que diariamente se presentan más denuncias de vulneración de estos derechos. No obstante, las violencias contra la mujer llegaron a ser un problema para los movimientos sociales transnacionales o para las acciones de redes solo hasta 1985. Para 1990 ya se consideraba un tema de la agenda internacional. En 1995 se celebró la Conferencia de la Mujer de las Naciones Unidas ${ }^{28}$. Ese ańo, los movimientos feministas y de derechos humanos asumieron una "postura de defensa común" frente a esta problemática (Keck y Sikkink, 2000, p. 225). No obstante, la coyuntura de los países ha marcado un gran obstáculo a la hora de brindar protección ante las violencias contra las mujeres. Los casos mexicano y colombiano, por ejemplo, que sufren fenómenos como el narcotráfico y el conflicto armado interno, muestran grandes limitaciones para proveer seguridad a las ciudadanas en su propio hogar. En Brasil y Argentina, donde las osc son fuertes, han logrado la construcción de data y marcos normativos. También es prudente mencionar que, en términos generales, en toda
América Latina, la cultura patriarcal juega un rol determinante. Casi que podría decirse que esta es responsable de las violencias contra las mujeres, que es de lo que nos ocuparemos en este apartado.

Ante la situación en América Latina, los movimientos de mujeres han tomado la delantera en el uso del estilo de comunicaciones de las redes, volviéndose modelo para las organizaciones de mujeres de todo el mundo (Keck y Sikkink, 2000, p. 229). Es preciso anotar que en México, Argentina y Brasil existe un fuerte movimiento social de mujeres.

\section{Méxıco}

No es un secreto que la cultura mexicana ha estado fuertemente arraigada al machismo, en donde el papel de la mujer se ve doblegado. Esto ha conllevado que la mujer se vea involucrada en hechos de violencia que incluyen el abuso sexual y su propia muerte. No obstante, desde que en 1998 México ratificó la Convención interamericana para Prevenir, Sancionar y Erradicar la Violencia contra la Mujer ${ }^{29}$, los gobiernos se han comprometido a brindar una mayor protección a la mujer. Por ello, y ante la grave situación que viven las mujeres en el país azteca, en el año 2007 se expidió la Ley General de Acceso de las Mujeres a una vida libre de violencia. Por su parte, la Cámara de Diputados, junto con el Instituto de Salud Pública, diseñó un manual que fomenta la creación de políticas públicas, para hacer

\footnotetext{
28 En la capital de la República Popular China, Beijin.

29 También conocida como Convención de Belém do Pará de la Organización de Estados Americanos (oEA), en 1994.
} 
frente a este problema. Estos manuales están dirigidos a los Centros de Reeducación para los violentos y las víctimas ${ }^{30}$, como parte del Programa de reeducación para víctimas y agresores de violencia de pareja. Esta jurisprudencia ha contado con la participación de organizaciones como el Centro de Justicia para las Mujeres (Miranda, 2016), que cuenta con atención jurídica y psicológica. En el Centro también se realizan investigaciones sobre estas conductas que permiten hacer una radiografía sobre la violencia intrafamiliar. Otras organizaciones como El Taller, denuncian la falta de compromiso político para investigar los crímenes, lo que genera mayor impunidad.

En aras de reducir la impunidad, y buscar mayor justicia ante la vulneración de estos derechos, algunas organizaciones como la Red Ciudadana de No Violencia y por la Dignidad Humana, se apersonaron de algunos casos. Quizá el de mayor trascendencia internacional fue el de Campo Algodonero, donde no solo se reconoció la desaparición forzada, sino que se tipificó el delito de feminicidio. El caso ocurrió en Ciudad Juárez, en la frontera con
Estados Unidos. Allí fueron encontrados, en fosa común, los cadáveres de Claudia Ivette González de 20 años, Laura Berenice Ramos de 17 y Esmeralda Herrera de 15, junto a otros cinco cuerpos femeninos.

Según investigaciones adelantadas por la Red Ciudadana de No Violencia y por la Dignidad Humana, la Asociación Nacional de Abogados Democráticos (ANAD), y el Comité de América Latina y el Caribe para la Defensa de los Derechos de la Mujer (CLADEM), todos los cuerpos registraban signos de violación y tortura. Fue entonces cuando la antropóloga e investigadora mexicana, Marcela Lagarde, retomó el término feminicidio con una connotación política, y logró la creación de la Comisión Especial de Feminicidio en el Congreso, para investigar el caso.

Sin embargo, el caso llegó ante la Corte Interamericana de Derechos Humanos (Corte IDH), en el 2007, mediante denuncias interpuestas por las mismas tres organizaciones que desde el inicio lideraron la investigación, en búsqueda de justicia. Estas osc trabajaron en red con sus pares ${ }^{31} y$, de esta manera,

30 Estos centros son establecidos por la Secretaría de Educación según lo establecido en el artículo 45 de la Ley General de acceso de las mujeres a una vida libre de violencia.

31 Las agrupaciones o personas que presentaron el documento Amicus curiae fueron: International Reproductive and Sexual Health Law Program de la Facultad de Derecho de la Universidad de Toronto (IRSHL Program) y el Centro por la Justicia y el Derecho Internacional (CEJIL), Track Impunity Always (TRIAL) y la Organización Mundial contra la Tortura (омст), un grupo de becarios del Instituto de Investigaciones Jurídicas de la Universidad Nacional Autónoma de México (UnAM), un Grupo de Derechos Humanos de la División de Posgrado de la unam, Women's Link Worldwide, Red de Mujeres de Ciudad Juárez A.C., Programa de Justicia Global y Derechos Humanos de la Universidad de los Andes, Programa de Derechos Humanos y la Maestría en Derechos Humanos de la Universidad Iberoamericana de México, Human Rights Watch, Horvitz \& Levy Llp, Comisión Internacional de Juristas, Amnistía Internacional, Centro de Derechos Humanos y la Escuela de Derecho de la Universidad de Essex, el Centro Internacional para la Justicia Transicional y Redress (Red Mesa de Mujeres de Ciudad de Juárez A.C. y CLADEM, 2010, pp. 15-16). 
utilizando la figura Amicus curiae ${ }^{32}$ aportaron pruebas y argumentos a la Corte.

El fuerte accionar de las organizaciones que llevaron a la demanda ante la Corte IDH finalmente arrojó grandes resultados. En 2009, México fue condenado por no garantizar la seguridad de las mujeres frente a ese patrón de violencia. Al decir de Rita Laura Segato ${ }^{33}$, se trató del "primer fallo [de esa Corte] de un caso de homicidio de mujeres por razones de género, y [...] en el cual el Estado tuvo responsabilidad independientemente de que no se haya podido probar que los crímenes fueron cometidos por agentes estatales" (Segato, 2011). No obstante, como ella misma lo reconoce, lo lamentable es que "no se logró que la Corte reconociera el término feminicidio" (Segato, 2011).

A pesar del gran precedente que fue la condena al Estado mexicano, la implementación del dictamen de la CIDH no ha sido eficaz. Según la denuncia de la Agencia de Comunicación e Información de la Mujer (CIMAC), el Estado mexicano no cumplió la sentencia de la Corte por cuanto estaba obligado a crear ${ }^{34}$ una página electrónica con información personal de todas las mujeres que desaparecieron en Chihuahua desde 1993, pero eso no ha ocurrido (ADITAL, 2010).

En consecuencia, queda evidenciada la oferta de valor que tienen las osc en los es- trados judiciales internacionales. La condena establecida a México, por la Corte, denota que esa oferta de valor logra impactos en diferentes ámbitos. Además, ese reconocimiento, tras el fallo, incentiva el trabajo para nuevas apuestas. Finalmente, cabe destacar el conocimiento técnico, legal y moral que tienen las organizaciones y que permite que estas trabajen en conjunto con el Estado para promover la protección de los derechos de las mujeres, pero también que este se sancione si no cumple con los mínimos establecidos.

\section{BRASIL}

Cualquier lector podría pensar que en el país de la samba y del Carnaval de Río, donde el culto al cuerpo es acentuado, no habría problemas por vulneración de derechos de las mujeres. Lamentablemente, no es así. Los registros de violaciones no son nuevos. Hoy, en 2016, hay mayores repertorios de acción colectiva y quizá más registros de denuncias. En concreto, la legislación es nueva. Solo en 2006, tras varios años de lucha, entró en vigor la Ley Maria da Penha que crea mecanismos para refrenar la violencia doméstica y familiar contra la mujer. Esta fue posible gracias al trabajo en conjunto de la sociedad civil y el Estado. La Ley 11.340 lleva este nombre debido a que Maria da Penha fue víctima de

\footnotetext{
32 Amicus curiae (amigos de la Corte). Documento con información técnica, de contexto o que se considere relevante en torno al caso y a través del cual se busca orientar y facilitar la toma de decisiones.

33 Rita Laura Segato es investigadora de nivel máximo del Consejo Nacional de Investigaciones Científicas y Tecnológicas de Brasil. Es miembro del Directorio de la ong brasileña AGENDE - Acciones en Género

34 En seis meses, a partir del 10 de diciembre de 2009.
} 
intento de homicidio, en dos ocasiones, por parte de su esposo, en 1983. A pesar de que el Tribunal de Jurados del estado de Ceará estableciera dos condenas al victimario, hubo impunidad: él quedó libre. Por lo que en 1998 Maria da Penha, junto con Cladem y el Centro por la Justicia y el Derecho Internacional (CEJIL), llevaron el caso ante la $\mathrm{CIDH}$, logrando así finalmente que el Estado fuera condenado -en 2001- por omisión, negligencia y tolerancia en relación con la violencia doméstica contra las mujeres brasileñas. En 2003, la CEDAW recomendó a Brasil adoptar sin demora una legislación sobre la violencia doméstica, hasta que finalmente se promulgó la ley, en 2006 (CLADEM, s.f.).

Ante la elaboración de informes acerca de la situación de la violencia basada en género en el país, quedó demostrado que el problema aún era latente y que se debían tomar medidas más efectivas para combatirlo. La CEDAw considera que el principal problema para enfrentar el feminicidio en Brasil es la falta de denuncia por parte de las víctimas, lo que no permite tener estadísticas de la situación (Branco, 2014). De todas maneras, el Instituto de Investigación Económica Aplicada (IPEA), que apoya técnicamente al Ministerio de Planificación y Presupuesto, establece una tasa anual de 5,82 mujeres asesinadas por cada $100 \mathrm{mil}$ mujeres, en 2014 (Branco, 2014). Esto, junto con otras denuncias, llevó a que, en 2015, se promulgara la Ley de Feminicidio, por medio de la cual el asesinato de mujeres fruto de la violencia doméstica o de la discriminación por causa del sexo, se considera un crimen atroz y se tipificara en el Código Penal, entre los tipos de homicidios calificados. Además, las penas fueron endurecidas (Canofre, 2015).

Un hecho que conmocionó al país carioca fue la violación colectiva a una adolescente de 16 años en una favela de Rio Janeiro, el pasado mes de mayo de 2016. El hecho desencadenó una serie de protestas frente a la Asamblea Legislativa, en las cuales participaron alrededor de 200 personas, en su mayoría mujeres. Al mismo tiempo, el uso de las redes sociales fue de gran importancia para repudiar los hechos. En Twitter fueron miles los mensajes enviados con la etiqueta "\#EstuproNaoÉCulpaDaVitima"35. De este modo, las movilizaciones impusieron, en la agenda, la situación ${ }^{36}$. El entonces presidente interino, Michel Temer, anunció la creación de un departamento para coordinar el combate de crímenes contra la mujer dentro de la Policía Federal. Días después, en las playas de Copacabana, Rio de Janeiro, se extendieron 420 bragas y varias fotografías de mujeres como símbolo de protesta. Las cifras señalan entre 5 y 6 violaciones por hora y 50 mil ataques sexuales al año (The Huffington Post, 2016). La exposición de protesta fue organizada por la ONG Rio da Paz; su presidente y fundador, Antonio Carlos Acosta, enfatizó que "tan importante cuanto combatir el abuso contra

\footnotetext{
35 La violación no es culpa de la víctima.

36 De acuerdo con datos del Foro Brasileńo de Seguridad Pública (FBSP), una mujer es violada cada 11 minutos en este país, y en 2014, 47.636 personas sufrieron una agresión sexual (The Huffington Post, 2016).
} 
la mujer es exigir acciones preventivas del poder público" (The Huffington Post, 2016). Por ello, Acosta exhorta a la implementación de políticas de educación y protección.

Los casos de violencia de género, que han llegado a instancias internacionales, han favorecido el fortalecimiento de la normatividad interna y han motivado a más osc a trabajar en la protección de las mujeres víctimas de este tipo de violencia. En este territorio, las osc han desarrollado conocimiento técnico para contar con estadísticas y presionar porque el Estado desarrolle data confiable que permita visibilizar la magnitud del problema. Esta capacidad hace parte de su oferta de valor. Es pertinente destacar que la investigación, el desarrollo y la innovación son claves para lograr transformaciones, y aquí los movimientos feministas, como parte de las osc van más allá de las denuncias: investigan e innovan.

\section{Colombia}

En Colombia, la violencia de género no escapa a la realidad ${ }^{37}$. Varias organizaciones, líderes, activistas y las mismas víctimas se han convertido en exponentes de esta problemática. La situación se visibiliza, simultáneamente, con movilizaciones y con lobby para presentar soluciones ante cada uno de los niveles del aparato estatal.

Los casos emblemáticos en Colombia son los de Rosa Elvira Cely y Natalia Ponce de León. En el primer caso, tras las violencias cometidas en el cuerpo de Cely, fueron las OsC las encargadas de estudiar el caso y generar propuestas para evitar hechos que atenten contra la dignidad de la mujer. En el segundo caso, la misma víctima ha sido quien ha liderado las actividades de lobby para nominar y normativizar este tipo de violencia. En uno y otro caso, es a través de osc y de las entidades estatales que se brinda apoyo jurídico y psicosocial a víctimas directas e indirectas.

A raíz del asesinato de Rosa Elvira Cely, en 2012, se realizaron varias movilizaciones para tipificar el feminicidio, en el Código Penal, y de esta manera lograr castigos ejemplarizantes para los agresores.

En las redes sociales y en las calles se lideraron varias movilizaciones. En twitter y facebook se promovió una marcha, que se realizó el 3 de junio de 2012, bajo el lema: "Ni una más: voces unidas-justicia para Rosa Elvira Cely” (El Espectador, 2012). A ella se unieron la Corporación Humanizando y la Mesa Nacional de Política Pública de Género (Corporación Humanizando, 2012), es protesta por el incremento de las violencias basadas en género. Tres años después, en 2015, realizaron otras marchas que tomaron como símbolo de justicia la vida de Rosa Elvira Cely y tuvieron como lema: "Ni una rosa más" (El Espectador, 2015). Paralelamente, desde 2012, Mar Candela Castilla, una activista y educadora urbana, realiza en el país la famosa "Marcha de las PUTAs"38. Esta marcha tiene como objetivo reivindicar el derecho de las

Es un hecho que las acciones que van contra la dignidad, la libertad y la vida de las mujeres tienen un arraigo cultural.

38 Acrónimo de: "Por una transformación auténtica y social". 
mujeres para tomar sus propias decisiones con respecto a su cuerpo (Género, 2013).

Ellas no se quedan en acciones de calle, también adelantan conferencias y talleres (Sáenz, 2013) para alcanzar diferentes públicos, en el proceso de concientización. Más aun, ejercen presión para la toma de decisiones. Lograron ejercer la presión necesaria para que tres años después, la Ley 1761 fuera aprobada. Ahora, en Colombia, el feminicidio es un delito autónomo, y por lo tanto se castiga cuando una mujer es asesinada, lo cual cambia el paradigma reinante en el derecho penal. Antes se hacía referencia al delito pasional, el cual desconocía este tipo de violencias y se limitaba la justicia a la esfera pública, imposibilitándola para la esfera privada. Hoy, al ser delito autónomo, se facilita la prevención, denuncia y sanción de este delito. Las penas pueden llegar hasta los cincuenta años de prisión (Presidencia de la República, 2015).

Si bien la promotora fue la representante a la Cámara Gloria Inés Ramírez, quien radicó el proyecto en el 2012 (Congreso Visible, 2012), es preciso anotar que varias organizaciones de mujeres adelantaron ejercicios de incidencia en el Congreso para que la bancada de mujeres presentara la iniciativa. Ramírez, como presidenta de la Comisión Equidad para la Mujer del Congreso, radicó el proyecto para tipificar el feminicidio como delito autónomo. No obstante, contó con el apoyo de la Organización de Mujeres CiJusticia, Fiscalía, Procuraduría, Defensoría, junto con onu Mujeres (Raigozo, 2013). También fue respaldada por la senadora Clara Rojas, y las representantes Ángela Robledo y Angélica Lozano (El Espectador, 2015). Robledo y Lozano se han caracterizado por ser activistas feministas en Colombia.

No obstante la realidad colombiana, y luego de sancionada la Ley, las pretensiones de anulación no se hicieron esperar. Un ciudadano interpuso una demanda a la 1761, pero el 8 de junio de 2016, la Corte Constitucional ratificó la ley con la que se tipificó el delito de feminicidio ${ }^{39}$ en el país. La ponencia de la magistrada Gloria Ortiz ratificaría la norma con el fin de que se continuase aplicándola en cualquier clase de violencia de género, incluyendo a las personas transgénero (Colprensa, 2016).

El feminicidio no es la única manera de violentar a las mujeres. En Colombia se han registrado ataques con agentes químicos que vulneran a la mujer física y psicológicamente. Por ejemplo, el ataque con ácido que sufrió Natalia Ponce de León, en marzo de 2014, visibilizó la problemática y llevó a la sociedad a tomar una acción a través de una fundación que lleva su nombre, para trabajar en pro de las víctimas de ataques con

\footnotetext{
39 La Ley 1761 de 2015 establece que existe feminicidio cuando la muerte de una mujer se da por su condición de mujer, de su identidad de género o cuando hayan antecedido algunas circunstancias que están explícitamente reseñadas como que haya existido una relación de familia o de amistad, o que se haya ejercido violencia sexual o patrimonial, entre otros (Colprensa, 2016).
} 
químicos. De la misma manera, se sensibilizó al Congreso para contar con una norma que tipificara el delito y castigara la acción (Fundación Natalia Ponce de León, 2015). Ante las denuncias, de las cuales tampoco se tenía registro oficial, y con lobby, la presión logró efectos; de esta manera, se tuvo el respaldo del representante a la Cámara Carlos Guevara, del partido MIRA. Él presentó el proyecto de ley, en el 2015 (Semana, 2015), y al año siguiente se promulgó la Ley de víctimas de ataques con ácido y agentes químicos, que tipificó el delito específico y también buscó endurecer las penas (Colprensa, 2016).

Esta ley trajo grandes cambios, tales como la tipificación del delito "lesiones con agentes químicos o ácido”, dentro del Código Penal. Las penas oscilan entre los 30 y 50 años, hay multas para los agresores que van desde 644 millones hasta los 1.932 millones de pesos, los agresores no tendrán ningún tipo de beneficio como reducción de pena o casa por cárcel y pagarán con ańos de cárcel aquellos comerciantes que vendan de manera ilegal este tipo de sustancias (la pena será entre 4 y 12 años de prisión) (Presidencia de la República de Colombia, 2016).

Podría decirse que en Colombia han sido las osc las que se han apersonado de la causa de las víctimas de las violencias basadas en género y de sus familias. Quizá ello se explica porque uno de sus roles está en lograr la visibilización de esos comportamientos que las vulneran. También los buscan prevenir. De ahí que las osc trabajen en el reconocimiento de derechos.

Con movilizaciones, los grupos de mujeres y las organizaciones que trabajan el tema logran poner en la esfera de lo público asuntos que, siendo privados, las vulneran. Ellas salen a la calle, sensibilizan y concientizan acerca de la importancia del tema, buscan el apoyo legislativo y presionan para que se haga realidad. Hacen lobby. Además, presionan por un cambio de paradigma en el derecho penal, como ha sucedido en Colombia con la nueva legislación al respecto. Luego, ellas mismas se encargan de que la normatividad para la protección de las mujeres no quede en letra muerta. En los dos casos estudiados en Colombia se puede evidenciar que se han dado pasos para evitar las violencias basadas en género, pero que aún es largo el camino para consolidar data suficiente que dé cuenta del número de fallos proferidos por estos dos delitos.

En concreto, se evidencia que la sociedad se organiza para transformar una situación y logra cambios no solo procedimentales sino sustanciales. En otras palabras, hacen innovación social.

\section{Argentina}

Si bien en el sur del continente podría decirse que el país gaucho cuenta con jurisprudencia casi tan antigua como la mexicana, de las más antiguas en Latinoamérica, las osc aún trabajan para lograr la eficiencia y efectividad en la implementación. Tienen una norma: Ley de Protección a las mujeres maltratadas de 2009, pero todavía las organizaciones, los colectivos y miles de personas salen a la calle en diferentes territorios. Buscan visibilizar el problema de las violencias de género. Por ejemplo, el 3 de junio de 2015, 
varias $\operatorname{OsC}^{40}$ se reunieron en la Plaza de los Dos Congresos, y en las principales ciudades de Argentina, para repudiar las violencias de género y los feminicidios (La Nación, 2015). Las movilizaciones se unificaron bajo el lema "Ni una menos", con el fin de visibilizar el problema porque las cifras han aumentado. Según la ONG Casa del Encuentro, desde 2008, más de 1.800 mujeres han sido asesinadas en el país (Galero, 2015).

Esta organización no gubernamental, fundada en 2003, lidera un proyecto feminista por los derechos humanos de todas las mujeres, y trabajó de manera mancomunada con la Fundación para el Estudio e Investigación de la Mujer (FEIM) para la promulgación de la ley de protección a las mujeres maltratadas. Aun así, según el Equipo Latinoamericano de Justicia y Género (ELA), los avances han sido pocos. No se ha creado el registro único, ni centralizado la información sobre feminicidios. No se han creado hogares de refugio para las víctimas. No existe coordinación entre las jurisdicciones ni entre los distintos poderes, y aún no se asigna un presupuesto adecuado para la puesta en marcha de un plan nacional contra la violencia (La Nación, 2015).

Para el 31 de mayo de 2016, los registros fueron contundentes: 275 mujeres asesinadas; esto es, una cada 30 horas; 317 personas quedaron sin madres, y 35 varones murieron intentando salvarlas de los feminicidas. La Casa del Encuentro hace lobby en el legislativo en pro del anteproyecto de la Ley Brisas, que busca reconocimiento económico para los hijos de víctimas de feminicidio (La Repúbli$c a, 2016)$. De igual manera, continúan con la marcha multitudinaria que se realizó en 3 de junio de 2016, y que ya se institucionalizó como una acción para reclamar por la aplicación de un plan de erradicación de la violencia, la elaboración de estadísticas oficiales y una reforma educativa que incluya esta temática (La Jornada, 2016).

En la Argentina, las osc cuentan con la capacidad técnica para producir y mejorar información referente a las violencias basadas en género, que el propio Gobierno no tiene. Desarrollan lobby para introducir reformas políticas y normativas tanto en lo penal como en lo educativo, precisamente sobre la base de sus investigaciones que son el pilar de sus propuestas para evitar la vulneración de los derechos de las mujeres.

\section{CONSIDERACIONES A MANERA DE CONCLUSIÓN}

Autores como Serrano reconocen que las osc tienen proximidad con la comunidad y la sociedad, y eso les permite tener un valor agregado. Les da mayor conocimiento de las necesidades y de las soluciones que se requieren en un territorio (2002, p. 74). Es ahí donde se incuba la oferta de valor de las osc. No obstante, como ellas mismas, esta puede pasar desapercibida.

40 ong Casa del Encuentro, Central de Trabajadores de Argentina (Cta), Movimientos de la Universidad de Buenos Aires (UBA), Bachillerato Popular Trans Mocha Celis, entre otras. 
Lo cierto es que con alianzas, y a través de los medios de comunicación masiva (prensa, radio y televisión), llaman la atención sobre los problemas de orden ambiental o violencias de género, como son los casos que aquí se han trabajado, para que se tomen decisiones de política local o internacional y, al mismo tiempo, se desarrolle jurisprudencia que permita evitar vulneraciones de derechos humanos.

En este escrito se han analizado dos temas: medio ambiente y violencias basadas en género en cuatro países latinoamericanos: México, Colombia, Brasil y Argentina, los cuales se han caracterizado por utilizar la extracción de recursos naturales como base de su desarrollo económico y, también, los cuatro presentan una cultura patriarcal que aviva la violencia doméstica y el abuso sexual hacia las mujeres. Lo que es peor, ha favorecido la aparición del feminicidio. Ante esta situación, se ha examinado el trabajo de las osc en uno y otro tema, encontrándose que estas son las que llevan la vocería para defender el medio ambiente y los derechos no solo de las mujeres sino con enfoque de género.

Lo que se encuentra al revisar diferentes casos en cada uno de los países, y por cada uno de los temas, es que los gobiernos se han quedado cortos al momento de proveer bienestar a la población. Es allí cuando las osc, con el conocimiento de las bases, se empoderan para concientizar, informar, conocer y buscar la participación en el proceso de toma de decisiones. Ello lo hacen con la legitimidad técnica, legal, social y moral que poseen, quizá por la dedicación y el altruismo que manejan cuando trabajan por los bienes públicos.

Por eso trabajan con persistencia y, en ocasiones, logran una sanción social individual/colectiva; en otras ocasiones, logran éxitos procedimentales y sustanciales. Unos para interactuar con el Estado y el mercado (o el sector empresarial). Los otros, para contar con jurisprudencia local, nacional e internacional que les permita proteger los derechos y garantizar la resiliencia de la sociedad.

Sin duda, tienen metodologías para elaborar data aun cuando no siempre sus estadísticas se convierten en oficiales ${ }^{41}$. Lo importante es que sus registros son la base fundamental para ahondar en investigaciones, dar relevancia a temas que deben entrar en la agenda de política pública local/nacional e internacional, según el caso. En la tabla 1 se detallan algunas ofertas de valor, pero aún queda una larga tarea de registro. Ese es un ejercicio que debe empezarse a realizar más temprano que tarde, puesto que con esa identificación se posibilitan varias cosas: el reconocimiento como instituciones, el reconocimiento de sus saberes, competencias y habilidades, la oportunidad de interactuar con otros agentes en multiámbitos (si se requiere), la creación de un acervo para considerar ofertas de cooperación Sur-Sur, el establecimiento de data que dé cuenta del peso específico del agente (en

41 Ejemplo de ello son las publicaciones que realizan diferentes organizaciones como Casa de la Mujer, que como parte de su oferta de valor publica el boletín bimensual denominado Ágata desde el 2014, con el fin de dar a conocer la situación frente a los derechos de las mujeres en Colombia (Casa de la Mujer, s.f.). 
TABLA 1. OFERTAS DE VALOR DE LAS ORGANIZACIONES DE LA SOCIEDAD CIVIL*

- Poseen conocimiento técnico-legal.

- Desarrollan innovación social.

- Su accionar se convierte en alarmas de control social.

- Desarrollan estrategias y tácticas de acción colectiva.

- Poseen habilidades para desarrollar redes y trabajo de diálogo multiactor.

- Promocionan escenarios de diálogo.

- Elaboran informes técnico-científicos, técnico-económicos, técnico-ambientales, entre otros.

- Estrategias de denuncia de vulneraciones de derechos.

- Estrategias para denunciar daño ambiental.

- Estrategias de pedagogía.

- Presentan propuestas alternativas (procedimentales, legales y políticas) para la elaboración de políticas públicas y, en algunos casos, hacen seguimiento a estas.

- Realizan trabajo de cabildeo (lobby) para la construcción de políticas públicas y establecimiento de nueva normativa.

- Robustecen el lenguaje y la normatividad** (código civil y penal).

- Construyen estándares o indicadores, metodologías y estrategias para hacer control social, veedurías, rendición de cuentas y accountability.

- Construyen data para la visibilización y denuncia de problemas (DH y ambientales).

- La información que estas producen es totalmente abierta.

- Realizan talleres para fortalecer capacidades.

- Hacen mapeo de recursos ambientales y de recursos endémicos.

* Es importante establece que la oferta de valor no es posible medirla a través de un solo indicador, dado que depende de la característica que se esté resaltando (valor, diferenciación o relevancia). Además, lo primero es precisar la construcción del concepto mismo.

** En el mundo es conocido que el término "Genocidio" es un desarrollo de las ONG de derechos humanos. De manera puntual, lo desarrolló Raphael Lemkin, uno de los activistas de Amnistía Internacional. De otro lado, se tiene el término "Feminicidio", desarrollado por la escritora Carol Orlock, en 1974, y utilizado públicamente por la feminista Diana Russell en 1976 ante el Tribunal Internacional de los Crímenes contra las Mujeres en Bruselas. Más adelante, la acepción política del término es introducida por Marcela Lagarde en el caso de Campo Algodonero en México.

términos económicos, políticos y sociales), entre otros.

En términos generales, el capital humano -involucrado en las osc-, más que ser un ejército que adelanta acciones colectivas de visibilización y de reivindicación de problemas, está constituido por equipos de trabajo de investigación y desarrollo que logran innovar socialmente. Institucionalizados y en red, conforman el pilar del capital social latinoamericano. Un capital social colaborativo, solidario y comprometido con el territorio y con sus habitantes.

Por ahora, sus ofertas de valor están opacadas, pero no quiere decir que no existan.
Aquí se ha dado evidencia de sus singularidades. De todas maneras, hay una urgencia de otras voces, de nuevos registros, de más trabajo empírico que dé cuenta de sus habilidades, competencias, investigaciones, desarrollos e innovaciones.

En los casos mencionados, tanto en medio ambiente como en las violencias basadas en género, se encontraron alianzas no solo entre organizaciones locales / nacionales sino también con organizaciones de la sociedad civil internacional, y al decir del Secretario General de World Alliance for Citizen Participation (Civicus) es necesario que "se construya un nuevo diálogo entre las ONG locales 
e internacionales para fortalecer las relaciones, además de buscar nuevas modalidades de ayuda para apoyar a las organizaciones" (Sriskandarajah, 2016).

De hecho, existen alianzas interesantes que posibilitan la existencia de nuevas ofertas de valor, como sucede con el desarrollo de estándares y la implementación de los mismos. Basta mirar el caso de Pronatura, en México, que introdujo el programa Neutralízate para disminuir la contaminación de las industrias, mejorando su responsabilidad social y disminuyendo los efectos sobre el medio ambiente.

Lo cierto es que el trabajo mancomunado que desarrollan las organizaciones, tanto en lo ambiental como para evitar las violencias basadas en género, presenta construcción de pedagogías ${ }^{42}$, promoción de innovación social, nuevo conocimiento ${ }^{43}$ para la toma de decisiones, estrategias para fortalecer capacidades, metodologías para crear bases, estrategias para trabajo con multiactores, trabajo de resiliencia; en otras palabras, una oferta de valor con sello. Por ello puede afirmarse que la evidencia encontrada posibilita confirmar la tesis planteada al inicio de la investigación. Es decir, las osc logran desarrollar tácticas y estrategias colectivas porque tienen conocimiento técnico-legal. Sus propuestas, en ocasiones, se suman a las decisiones que toma el Estado, pero otras veces acuden a la norma para par- ticipar con alternativas y para ello elaboran informes según el caso (socioeconómicos, ecológicos, de vulneración de derechos y hasta con estadísticas alternativas).

Lo concreto con cada una de las organizaciones en México, Brasil, Colombia y Argentina es que sus ofertas de valor tienen tangibles e intangibles, y reconocerlas posibilita la existencia y sostenibilidad de ese abanico de organizaciones que conforman la sociedad civil. En cada territorio hay registros de que la oferta de valor de las osc les ha permitido ser exitosas (en términos procedimentales o sustanciales). Ello les garantiza lograr recursos de donantes, credibilidad entre los socios y legitimidad democrática. Con y por esas ofertas de valor, las osc logran empoderarse con nuevos emprendimientos sociales, $y$ pueden desarrollar innovaciones sociales tan necesarias en la región.

\section{REFERENCIAS}

adital (2010). Adital: Noticias de América Latina y el Caribe. Recuperado de http://site.adital.com.br/ site/noticia.php?lang=ES\&cat $=75 \& \mathrm{dt}=2010-06$ $14 \& \operatorname{cod}=48561$

Asociación de Investigación y Especialización sobre temas Iberoamericanos/Europa (AIETI) (2014). Europa y América Latina deben aunar esfuerzos en la lucha contra los feminicidios. Recuperado

\footnotetext{
42 Pedagogías que van desde la socialización de temáticas de interés por medio de talleres, pedagogías ambientales, pedagogías lúdicas para el reconocimiento de derechos y deberes, así como de espacios para hacer control social.

43 En Colombia, como se mencionó, el trabajo de las osc permitió que finalmente el Congreso de la República tipificara el feminicidio como un delito penal y lo incluyera en el Código. Esto es nuevo conocimiento.
} 
de http://www.aieti.es/europa-y-america-latinadeben-aunar-esfuerzos-en-la-lucha-contra-losfeminicidios

Agencia de Informaciones Mercosur (AIM) (2016). Conferencia en Paraná: "El glifosato daña". Recuperado de http://www.aimdigital.com.ar/2016/05/23/ conferencia-en-parana-el-glifosato-dana/

Álvarez, D. (2016). Afectadas por la minera brasilera Vale difundieron su lucha en Mendoza. La Izquierda Diario. Recuperado de http://www. laizquierdadiario.com/Afectadas-por-la-minerabrasilera-Vale-difundieron-su-lucha-en-Mendoza

Atentas, J. y Vivas, E. (2009). Resistencias globales: de Seatlle a la crisis de Wall Street. Madrid: Editorial Popular.

ввС Mundo (2016). Brasil: las 4 causas del desplome de la mayor economía de América Latina. BBC. Recuperado de http://www.bbc.com/mundo/ noticias/2016/03/160303_brasil_causas_del_ desplome_economico_gl

Boisier, S. (1995). Sociedad civil, actores sociales y desarrollo regional. Santiago de Chile: CEPAL, ILPES (Instituto Latinoamericano y del Caribe de Planificación Económica y Social). Recuperado de http://repositorio.cepal.org/bitstream/handle/11362/9663/S9500092_es.pdf?sequence=1

Branco, S. C. (2014). Unitedexplanations.org. Recuperado de http://www.unitedexplanations. org/2014/05/27/has-oido-hablar-sobre-el-femenicidio-en-brasil/\#

Canofre, F. (2015). Brasil aprobó la ley del feminicidio pero sin consenso sobre si combatirá la violencia de género. Recuperado de https://es.globalvoices. org/2015/04/15/brasil-aprueba-la-ley-del-feminicidio-pero-sin-consenso-sobre-si-combatira-laviolencia-de-genero/

Caracol Radio (2016). Estudio de Cormacarena permitió suspensión de licencia para explorar pe- tróleo en Caño Cristales. Bogotá: Caracol Radio. Recuperado de http://caracol.com. co/programa/2016/04/15/6am_hoy_por_ hoy/1460724405_651067.html

Casa de la Mujer (s.f.). Publicaciones: Boletines de Casa de la Mujer. Recuperado de http://www.casmujer. com/boletines

CCONG (2016). ¿Estamos listas para la agenda de desarrollo sostenible? Oferta de valor de la ONG-OSC 2014-2015. Bogotá: CCONG.

CEDAm (2015). Organizaciones desaprueban la autorización otorgada por Semarnat a proyecto para almacenar roca de Los Tuxtlas. Recuperado de http://www.cemda.org.mx/organizaciones-dela-sociedad-civil-desaprueban-la-autorizacionotorgada-por-semarnat-a-proyecto-para-almacenar-roca-de-los-tuxtlas/

CEDAM (2016). Las organizaciones de la sociedad civil apoyan la creación del Área Natural Protegida Caribe Mexicano y dan elementos técnicos para reforzarla. Recuperado de http://www.cemda. org.mx/las-organizaciones-de-la-sociedad-civilapoyan-la-creacion-del-area-natural-protegidacaribe-mexicano-y-dan-elementos-tecnicos-parareforzarla/

Centro de Estudios para la Justicia Social Tierra Digna (2016). Tierradigna.org. Recuperado de http:// tierradigna.org/2016/06/16/sin-efecto-delimitacion-de-aem-en-colombia/

CEPAL (s.f.). Papel de las organizaciones intergubernamentales y no gubernamentales en la promoción de la cooperación regional y subregional del desarrollo sostenible. Recuperado de http://www.cepal. org/publicaciones/xml/8/9628/lcl1613e_3.pdf Change (s.f.). SEMARnat: iProtejan los arrecifes de coraly Los Tuxtlas en Veracruz! \#ConservaVeracruz. México. Recuperado de https://www.change.org/p/ 
ing-rafael-pacchiano-alam \%C3\%A1n-protejalos-arrecifes-de-coral-y-la-selva-de-veracruz

CIA (2016). Library. The world factbook. Recuperado de https://www.cia.gov/library/publications/ the-world-factbook/geos/mx.html

CLADEM (s.f.). Cladem.org. Recuperado de http:// www.cladem.org/programas/litigio/litigiosinternacionales/12-litigios-internacionalesoea/27-caso-maria-da-penha-brasil-violenciadomestica-contra-las-mujeres

Colprensa (2016). Corte ratificó la ley que creó el delito de feminicidio. El Colombiano. Recuperado de http://www.elcolombiano.com/colombia/corteratifico-la-ley-que-creo-el-delito-de-feminicidioBC4343056

Colprensa (2016). Natalia Ponce volvió a descubrir su rostro luego del ataque. El Colombiano. Recuperado de http://www.elcolombiano.com/colombia/santos-promulgo-ley-natalia-ponce-queendurece-penas-a-ataques-con-acido-JC3455920

Congreso Visible (2012). Congreso Visible. Recuperado de http://congresovisible.org/agora/post/senadora-gloria-ines-ramirez-radica-proyecto-de-leypara-tipificar-el-feminicidio-como-delito/3977/

Contagio Radio (2016). Impactos del Fraking en 6 países de Latinoamérica. Recuperado de http://www. contagioradio.com/impactos-del-fracking-en6-paises-de-latinoamerica-articulo-31765/

Coporación Humanizando (2012). Humanizando. Recuperado de http://www.humanizando.com/ documentos/24-boletin-de-prensa-14

Corresponsables México (2016). Chinoin logra cero emisiones de la mano de Pronatura. Recuperado de http://mexico.corresponsables.com/actuali$\mathrm{dad} /$ chinoin-logra-cero-emisiones-de-la-manode-pronatura

Corte Interamericana de Derechos Humanos (2012). Pueblo Indígena Kichwa de Sarayaku Vs. Ecua- dor, Serie C-245. Recuperado de http://corteidh. or.cr/docs/casos/articulos/seriec_245_esp.pdf

Diario La República (2016). En un año hubo un feminicidio cada 30 horas en la Argentina. Recuperado de http://diariolarepublica.com.ar/new/sociedad/2016/06/02/en-un-ano-hubo-un-feminicidio-cada-30-horas-en-la-argentina/

Diario Momarandu (2016). Reclaman tratamiento "urgente" de Ley de Humedales . Diario Momarandu. Recuperado de http://www.momarandu. com/amanoticias.php? $\mathrm{a}=7 \& \mathrm{~b}=0 \& \mathrm{c}=151580$

Ecologistas en acción (2015). Chico Mendes. Recuperado de http://www.ecologistasenaccion.org/ article1158.html

El Espectador (2012). A Rosa Elvira la atacó un conocido. El Espectador. Recuperado de http://www. elespectador.com/noticias/judicial/rosa-elviraataco-un-conocido-articulo-350008

El Espectador (2015). Aprobada Ley Rosa Elvira Cely que castiga hasta con 50 años los feminicidios. El Espectador. Recuperado de http://www. elespectador.com/noticias/politica/aprobadaley-rosa-elvira-cely-castiga-hasta-50-anos-losarticulo-564105

El Espectador (2015). Bogotá marchará contra el feminicidio bajo la campaña “' $\mathrm{iNi}$ una Rosa más!” El Espectador. Recuperado de http://www.elespectador.com/noticias/bogota/bogota-marcharacontra-el-feminicidio-bajo-campana-ni-u-articulo-563269

El Espectador (2016). Corte Constitucional frena en seco la locomotora minera. El Espectador. Recuperado de http://www.elespectador.com/ noticias/medio-ambiente/corte-constitucionalfrena-seco-locomotora-minera-articulo-637308 Esteva, G. (2010). Development. En Sachs, W. The Development Dictionary (pp. 12-13). Zed Books. 
Frasson-Quenoz, F. (2015). Autores y teorias de relaciones internacionales: una cartografía. Bogotá: Universidad Externado de Colombia.

Fundación Natalia Ponce de León (2015). Fundación Natalia Ponce de León. Recuperado de http:// www.fundacionnataliaponcedeleon.org/sobrenosotros/

Fundación Vida Silvestre (2013). Organizaciones ambientalistas advierten pocos avances en la aplicación de la Ley de Bosques. Recuperado de http:// www.vidasilvestre.org.ar/?6881/Organizacionesambientalistas-advierten-pocos-avances-en-laaplicacin-de-la-Ley-de-Bosques

Galero, C. (2015). Clamor contra los feminicidios en Argentina. El Mundo. Recuperado ede http:// www.elmundo.es/internacional/2015/06/03/5 56f760ee2704e8c538b459a.html

Género, E. (2013). Eq Género. Recuperado de http:// www.eqgenero.com/la-marcha-de-las-p-u-t-as-bogotal

Gómez Lee, M. (2005). Las patentes sobre biodiversidad en el TLC: negocio inconsulto. OASIS (11), 103 134. Recuperado de http://revistas.uexternado. edu.co/index.php/oasis/article/view/2396/2036

Grupo Sur Red de Incidencia Ue-América Latina y el Caribe (2015). Diálogo bi-regional UE-CELAC suspende en la luch a contra el feminicidio. Recuperado de http://www.gruposur.org/dialogo-biregional-ue-celac-suspende-en-la-lucha-contrael-feminicidio/

Instituto Chico Mendes de Conservación de la Biodiversidad (2016). Icmbio.gov.br. Recuperado de http://www.icmbio.gov.br/portal/ultimasnoticias/20-geral/7860-criada-primeira-reservadedicada-a-uma-unica-especie-aquatica

Kaldor, M. (2005). La sociedad civil global. Una respuesta a la guerra. Madrid: Tusquets Editores S.A.
Keane, J. (2009). La sociedad civil global y el gobierno del mundo. Madrid: Editorial Hacer.

Keck, M. y Sikkink, K. (2000). Activistas sin fronteras. México: Editorial Siglo xxi.

La Jornada (2016). Miles marchan contra el feminicidio en Argentina. La Jornada. Recuperado de http:// www.jornada.unam.mx/ultimas/2016/06/03/miles-marchan-contra-el-feminicidio-en-argentina

La Nación (2015). Casi no se aplica la ley contra los femicidios. La Nación. Recuperado de http://www. lanacion.com.ar/1799664-casi-no-se-aplica-laley-contra-los-femicidios

La Nación (2015). Una multitud participó de la marcha \#NiUnaMenos en el Congreso y distintos puntos del país. La Nación. Recuperado de http://www. lanacion.com.ar/1798439-empezo-la-marchaniunamenos-y-la-gente-se-acerca-al-congreso

López Leyva, M. (012). Los movimientos sociales y su influencia en el ciclo de las políticas públicas. Región y Sociedad, 24 (55),159-197. Recuperado de http://www.scielo.org.mx/scielo.php?script=sci_ arttext\&pid=S1870-39252012000300005

Lutz Ley, A. y Salazar Adams, A. (2011). Medio ambiente y organizaciones de la sociedad civil: análisis de las redes civiles ambientalistas en Hermosillo, Sonora. Región y Sociedad, XXIII (51), 5-41. Recuperado de http://www.redalyc. org/pdf/102/10220221001.pdf

Maldonado, C. (2002). Filosofia de la sociedad civil. Bogotá: Siglo del Hombre Editores-Universidad Libre.

Marín, M. (2009). Dos contextos de intervención de la sociedad civil. A propósito de su participación en la toma de decisiones ambientales. Revista Ópera (9), 241-270. Recuperado de http://www.redalyc. org/pdf/675/67515007014.pdf

Marín Aranguren, E. M. (2013). Consulta Previa: la punta del iceberg de los dilemas sociales frente 
a la extracción de recursos naturales en Colombia. En González Espinosa, A. C. Los retos de la gobernanza minero-energética (vol. 43, pp. 65104). Bogotá, Colombia: Universidad Externado de Colombia.

Marín Aranguren, E. M. (2016). Las voces de la sociedad civil: narrativas sobre la cuestión mineroenergética. En Henao, J. C. y González Espinosa, A. C. Minería y Desarrollo (vol. 4, pp. 513-556). Bogotá, Colombia: Universidad Externado de Colombia.

Miranda, J. (2016). Urge reeducar violentos. Diario de Morelos. Recuperado de https://www.diariodemorelos.com/noticias/urge-reeducar-violentos

No a la Mina (2016a). Interviene el gobierno para solucionar el conflicto con minera Media Luna. Recuperado de http://www.noalamina.org/latinoamerica/ mexico/item/15529-interviene-el-gobierno-parasolucionar-el-conflicto-con-minera-media-luna

No a la Mina (2016b). Comunidad aborigen denuncia que una minera avanza sobre su territorio por un aval otorgado por Fellner. Recuperado de http:// www.noalamina.org/mineria-argentina/jujuy/ item/15161-comunidad-aborigen-denunciaque-una-minera-avanza-sobre-su-territorio-porun-aval-otorgado-por-fellner

No a la Mina (2016c). ONG y movimientos sociales de Brasil repudian acuerdo entre empresa minera y gobierno. Recuperado de http://www.noalamina.org/latinoamerica/brasil/item/15299-ong$s-y$-movimientos-sociales-de-brasil-repudianacuerdo-entre-empresa-minera-y-gobierno

Periódico Estadao (2011). Greenpeace protesta contra exploração de petróleo na empresa de Eike Batista. Estadao. Recuperado de http://sustentabilidade.estadao.com.br/noticias/geral,greenpeaceprotesta-contra-exploracao-de-petroleo-na-empresa-de-eike-batista, 767118
Peruzzotti , E. y Smulovitz, C. (2002). Accountability social: la otra cara del control. En Controlando la politica: ciudadanos y medios en las nuevas democracias latinoamericanas. Buenos Aires: Temas. Recuperado de https://iniciativatpa. files.wordpress.com/2010/06/5-accountabilitysocial-smulovitz-y-preuzzotti.pdf

Presidencia de la República (2015). Normativa: Ley 1761, "Por la cual se crea el tipo penal de feminicidio como delito autónomo y se dictan otras disposiciones" (Rosa Elvira Cely). Recuperado de http://wp.presidencia.gov.co/sitios/normativa/ leyes/Documents/LEY \%201761 \%20DEL \%20 06\%20DE \%20JULIO \%20DE \%202015.pdf

Presidencia de la República de Colombia (2016). Normativa: Ley 1773 de 2016 -Ley de Victimas de Ataques con ácido con Agentes Químicos, Ácido o Sustancias Similares-. Recuperado de http:// es.presidencia.gov.co/normativa/normativa/ LEY \% 201773 \%20DEL \%206\%20DE \%20ENERO \%20DE \%202016.pdf

Raigozo, C. (2013). Voz: la verdad del pueblo. Recuperado de http://www.semanariovoz.com/2013/09/27/ gloria-ines-ramirez-radico-proyecto-de-ley-contra-el-feminicidio-en-colombia/

Red Mesa de Mujeres de Ciudad de Juárez A.C. y Cladem (2010). Campo algodonero: análisis y propuestas para el seguimiento de la sentencia de la Corte Interamericana de Derechos Humanos. Recuperado de http://www.cladem.org/images/ archivos/publicaciones/nacionales/mexico/Campo_algodonero_ES.pdf

Revista Forbes (2015). 4 retos económicos para la Argentina de Macri. Revista Forbes. Recuperado de http://www.forbes.com.mx/4-retos-economicospara-la-argentina-de-macri/

Roitter, M. (2005). El tercer sector como representación topográfica de la sociedad civil. En Arditi, 
B. ¿Democracia post-liberal?: el espacio político de las asociaciones. Barcelona: Anthropos.

Sáenz, V. (2013). Habla la líder de la 'Marcha de las Putas'. El Tiempo. Recuperado de http://www.eltiempo.com/archivo/documento/CMS-12672484

Segato, R. (2011). Femigenocidio y feminicidio: una propuesta de tipificación. Revista Herramienta, 49. Recuperado de http://www.herramienta.com. ar/revista-herramienta-n-49/femigenocidio-yfeminicidio-una-propuesta-de-tipificacion

Semana (2015). La ley por la que luchó Natalia Ponce de León. Semana. Recuperado de http://www. semana.com/nacion/articulo/congreso-aproboproyecto-de-ley-para-castigas-ataques-con-acido/451207-3

Semana Sostenible (19 de abril de 2016). Revocan la licencia petrolera en la Macarena. Recuperado de http://sostenibilidad.semana.com/medioambiente/articulo/revocan-la-licencia-petroleraen-la-macarena/34933

Serrano Oñate, M. (2002). Las ONG en la encrucijada: del Estado de Bienestar a la franquicia del Estado. En Blanco, M. R. Las ong y la política (pp. 66-94). Madrid: IsтMo.
Sriskandarajah, D. (2016). Five things international $\mathrm{NGOS}$ are blamed for. Recuperado de http://news.trust. org/item/20160613131744-uctfe/

The Huffington Post (2016). Extienden 420 bragas en la playa de Copacabana en protesta contra violaciones. The Huffington Post. Recuperado de http://www.huffingtonpost.es/2016/06/07/ bragas-copacabana-violaci_n_10338490.html

The Huffington Post (2016). La violación colectiva a una joven consterna Brasil y expande la indignación en las calles. The Huffington Post. Recuperado de http://www.huffingtonpost.es/2016/05/28/ violaciones-masivas-brasil_n_10179894.html

UNDP (s.f.). Desarrollo Humano en Argentina. Proyectos/Desarrollo Humano. Recuperado de http:// www.ar.undp.org/content/argentina/es/home/ operations/projects/human_development.html Universidad del Valle (2015). Metabolismo social y conflictos ambientales en paises latinoamericanos. Recuperado de https://www.youtube.com/ watch?v=MAYYHNL 5 wvg

Vidal Beneyto, J. (2003). Hacia una sociedad civil global. Madrid: Tauros. 